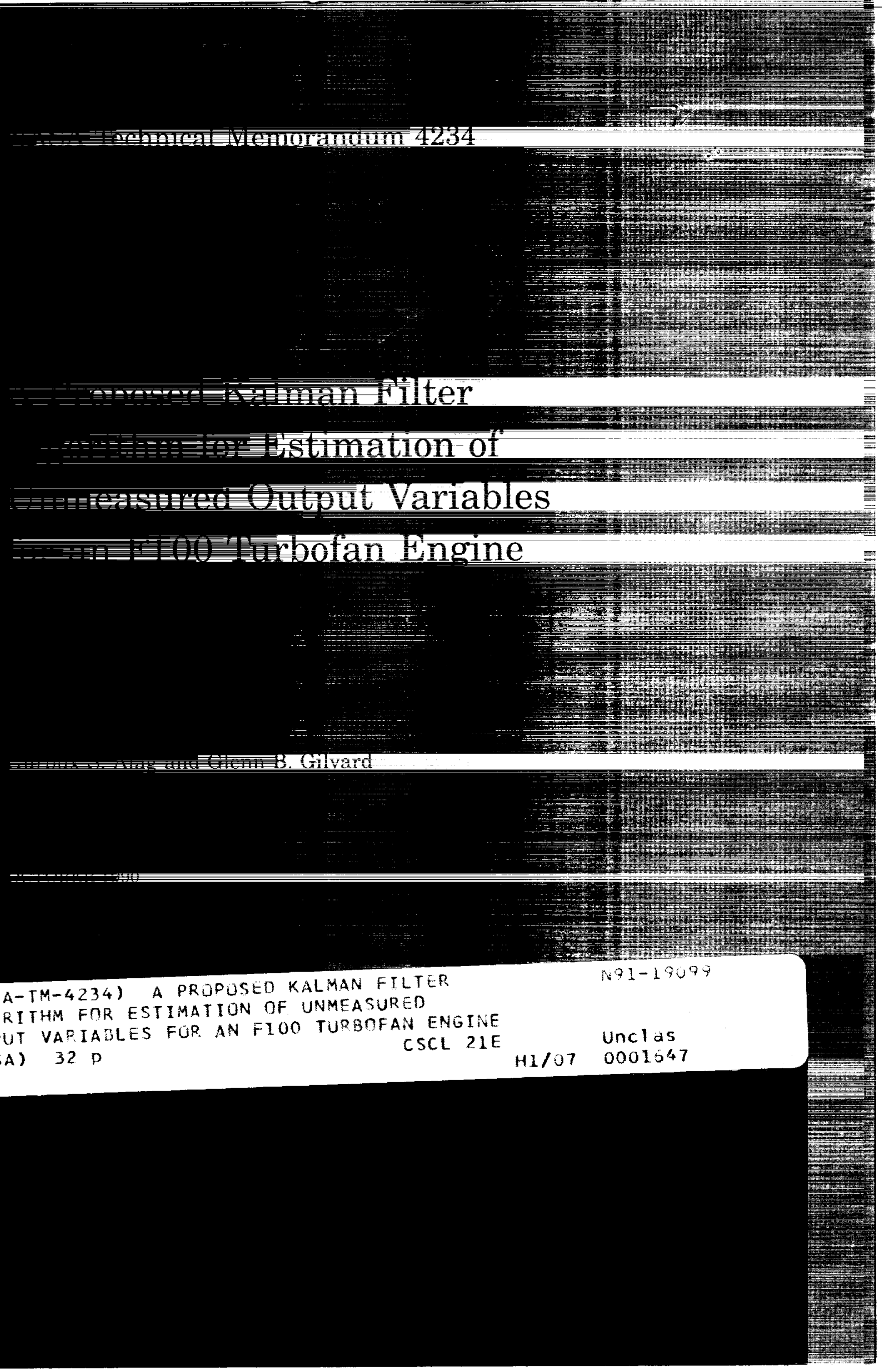


NASA Technical Memorandum 4234

\section{A Proposed Kalman Filter Algorithm for Estimation of Unmeasured Output Variables for an F100 Turbofan Engine}

Gurbux S. Alag

PRC System Service,

Edwards, California

Glenn B. Gilyard

Ames Research Center

Dryden Flight Research Facility

Edwards, California

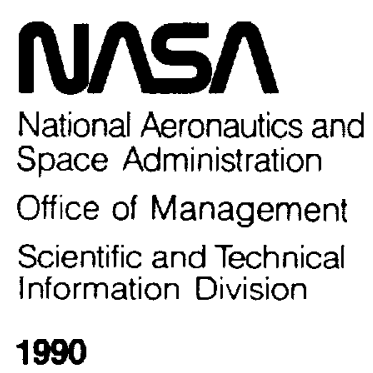




\section{I}




\section{A PROPOSED KALMAN FILTER ALGORITHM FOR ESTIMATION OF UNMEASURED OUTPUT VARIABLES FOR AN F100 TURBOFAN ENGINE}

\author{
Gurbux S. Alag* \\ PRC Systems Service \\ Edwards, CA
}

\author{
Glenn B. Gilyard** \\ NASA Ames Research Center \\ Dryden Flight Research Facility \\ Edwards, CA
}

\begin{abstract}
To develop advanced control systems for optimizing aircraft engine performance, unmcasurable output variables must be estimated. The estimation has to be done in an uncertain environment and be adaptable to varying degrees of modeling errors and other variations in engine behavior over its operational life cycle. This paper presents an approach to estimate unmeasured output variables by explicitly modeling the effects of off-nominal engine bchavior as biases on the measurable output variables. A state variable model accommodating off-nominal behavior is developed for the engine, and Kalman filter concepts are used to cstimate the required variables. Results are presented from nonlinear engine simulation studics as well as the application of the estimation algorithm on actual fight data. The formulation presented has a wide range of application since it is not restricted or tailored to the particular application described in the paper.
\end{abstract}

\section{Nomenclature}

$$
\begin{gathered}
A, B, C, D, \\
F, G, H
\end{gathered}
$$

\section{system matrices in state} variable representation

$A_{J}$

$b$

$\mathrm{CDF}$

nozzle arca, in.

bias vector

component deviation factors

Senior Control Engineer.

**Aerospace Engineer. Member ALAA.

Copyright $(\mathcal{C} 1990$ by the American Institute of Aeronautics and Astronautics, Inc. No copyright is asserted in the United States under Title 17, U.S. Code. The U.S. Government has a royalty-free license to exercise all rights under the copyright claimed herein for Governmental purposes. All other rights are reserved by the copyright owner.

$\begin{array}{ll}C I V V & \text { fan inlet guide vane angle, deg } \\ \text { DEEC } & \text { digital electronic engine control } \\ D_{N O Z} & \text { nozzle drag, lb } \\ D_{R A M} & \text { ram drag, lb } \\ d & \text { difference } \\ \text { E } & \text { expectation operator } \\ \text { EMD } & \text { engine model derivative } \\ e & \text { state error vector } \\ F_{G} & \text { gross thrust, lb } \\ F_{N P} & \text { net propulsive thrust, lb } \\ \text { I } & \text { identity matrix } \\ K & \text { Kalman filter gain } \\ N_{1} & \text { fan rotor speed, rpm } \\ N_{2} & \text { core rotor speed, rpm } \\ P & \text { Riccati matrix } \\ P B & \text { bumer static pressure, lb/in }{ }^{2} \\ \text { PLA } & \text { power lcver angle, deg } \\ \text { PSC } & \text { performance secking control } \\ \text { PSM } & \text { propulsion system model } \\ P_{T_{2} 5} & \text { compressor inlet total pressure, lb/in }{ }^{2} \\ P_{T_{5}} & \text { low lurbinc inlet pressure, lb/in } \\ P_{T_{6}} & \text { afterburner inlet total pressure, } \mathrm{lb} / \mathrm{in}^{2} \\ P_{T_{7}} & \text { nozrle throat total pressure, } \mathrm{lb} / \mathrm{in}^{2} \\ Q & \text { state noise covariance matrix } \\ R & \text { measurement noisc covariance matrix } \\ R_{C V V} & \text { compressor stator vane angle, deg } \\ S M_{F} & \text { fan stall margin } \\ & \end{array}$




$\begin{array}{ll}S M_{H C} & \text { high compressor stall margin } \\ \text { SOAPP } & \text { state-of-the-art propulsion program } \\ \text { SSM } & \text { steady state model } \\ \text { SVM } & \text { state variable model } \\ T M T & \text { turbine metal temperature, }{ }^{\circ} \mathrm{R} \\ T_{T_{2.5}} & \text { compressor inlet total temperature, }{ }^{\circ} \mathrm{R} \\ T_{T_{3}} & \text { bumer inlet total temperature, }{ }^{\circ} \mathrm{R} \\ T_{T_{4}} & \text { burner exit total temperature, }{ }^{\circ} \mathrm{R} \\ T_{T_{4.5}} & \text { low turbine inlet total temperature, }{ }^{\circ} \mathrm{R} \\ T_{T_{6}} & \text { afterburner inlet total temperature, }{ }^{\circ} \mathrm{R} \\ T_{T_{7}} & \text { nozzle throat total temperature, }{ }^{\circ} \mathrm{R} \\ u & \text { control input vector } \\ W C_{F A N} & \text { corrected fan air flow, lb/sec } \\ W C_{H P C} & \text { corrected compressor air flow, lb/sec } \\ W_{F} & \text { main burner fuel flow, lb/hr } \\ w_{1} & \text { state excitation noise } \\ w_{2} & \text { measurement noise } \\ x & \text { state vector } \\ y & \text { output vector } \\ y_{a u x} & \text { vector of auxiliary, (unmeasured) } \\ z & \text { output variables } \\ \delta & \text { augmented state vector } \\ & \text { variation from trim values }\end{array}$

\section{Superscripts}

$\mathrm{T}^{\prime}$

^

$\cdot$

\section{Subscript}

$b$

$m$

N.L.

$t$

1

output bias term

flight or simulated data

nonlincar

trim, initial, or steady state

augmented system matrices

\section{Introduction}

Efforts to improve aircraft turbine engine efficiency have led to an increase in the number of engine control variables and a corresponding increase in the complexity of control laws. Control laws for current engines are based on classical control theory and empirical schedules for a nominal engine. Classical control theory has served well for the current and older engines. The design of future fighters as multifunction aircraft and development of integrated flight/propulsion control systems, however, require sophisticated control systems capable of obtaining the maximum performance from the engine. Optimal control techniques using modem control theory are required to obtain additional gains in engine performance. For modern aircraft, accounting for engine variations through designs based on predetermined control schedules is increasingly difficult because of the increased complexity and increased number of control effectors on the engines. Engine-to-engine component variations, engine deterioration, and off-nominal behavior are difficult to account for in the design of control system schedules.

An adaptive control algorithm, which computes optimal control trim settings for the engine while maximizing the vehicle performance for a given flight condition, accounts for these variations better than gain scheduling. Specifically, an adaptive trim control system computes and applies an incremental steady state trim to enhance the engine performance. ${ }^{1}$

For over a decade, the National Aeronautics and Space Administration (NASA) Ames Research Center, Dryden Flight Research Facility (Ames-Dryden) has conducted a multidisciplinary flight rescarch program on an F-15 airplane. Significant portions of this research involved the flight evaluation of advanced propulsion control concepts in programs such as digital electronic engine control (DEEC), the F100 engine model derivative (EMD), and highly integrated digital elcctronic control (HIDEC). ${ }^{2}$ The increased performance and improved fucl economy demonstrated on the F-15 HIDEC rescarch vehicle is the basis of the performance sceking control (PSC) program, which will provide additional improvements in these areas.

Ames-Dryden, McDonnell Aircraft Company, and Pratt \& Whitney are currently developing and demonstrating an adaptive PSC system in flight on a NASA F-15 airplane powered by F100 EMD engines. The PSC system optimizes aircraft performance by applying adaptive trim control to the propulsion system opcrating in a pscudo-steady-state cruise mode. The trim schedules are determined for a highly nonlin- 
ear propulsion system which has system and measurement noise, unmeasurable parameters, and sensitivity to normal deterioration over its life cycle.

Figure 1 shows the adaptive trim control structure used for the PSC. The state variable model (SVM) and the steady-state model (SSM) which model the dynamic and steady-state behavior of a nominal engine, are key components of the system. These models are stored onboard the aircraft in a table look-up form and are discussed in more detail in the following section.

These models are used in formulating the propulsion system model (PSM) which represents a small perturbation model of the actual flight propulsion system. The PSM contains relations which provide estimates of performance measures (such as augmentor effects, thrust, and stall margins) and constraint equations. A linear programming algorithm is used to find the optimal solution and these commands are then applied to the engine through the DEEC.

The values of output variables, which are often not directly measurable, are needed for the optimization algorithm used in the PSC. These variables are estimated under changing levels of engine health, manufacturing differences between engines, and other offnominal bchavior. Accommodating these performance variations in engines has been investigated in two recent studies. ${ }^{3,4}$

Refcrence 3 presents an algorithm for estimating the cause and level of off-nominal engine operation by using a Kalman filter algorithm to estimate five engine factors. These five factors, referred to as component deviation factors (CDF), compensate for off-nominal performance. These factors were estimated by treating them as biases, and the original state vector was augmented to give five additional states. ${ }^{5}$ These five factors are not explicitly used in the optimization algorithm and their physical significance is unclear because the formulation does not account for biases, prediction crrors, and Reynolds number effects. Since the coefficients with respect to the CDF parameters are required in the Kalman filter development, the CDF formulation requires detailed modeling of the off-nominal process. A flight data evaluation of this algorithm is described in Ref. 6.

In Ref. 4, a component tracking filter is used to achieve the model accuracy required to optimize engine performance. The component tracking filter com- bines the concept of state tracking and adaptive filtering to minimize engine/model mismatch. It is based on a frequency decomposition of the differences between the sensed engine parameters and the model values.

This paper presents another method of accounting for off-nominal operation and other modeling inaccuracics. Since any variation from the nominal model would result in a change in the sensed values of the measured outputs, the off-nominal behavior of an engine is characterized in terms of these changes. Uncertainties associated with any given engine will be represcnted as systematic errors in the sensed output parameters. These systematic errors will be accounted for by augmenting the original state equation with bias states. A Kalman filter is used to estimate the original engine states and the bias states. The Kalman filter inputs are measurements from standard F100 engine control instrumentation. The auxiliary output equations for the unmeasurcd output variables are modified to include the effect of the bias states.

The concept is validated by applying the developed filter on both simulation and flight data. For the simulation data case, the output variables were estimated by using the data from the available nonlinear engine simulation. Both a nominal engine and an engine in which intentional degradation was introduced to create off-nominal bchavior were considered. For the flight data case, the estimation process was performed using actual flight data from an F-15 aircraft. For this case, comparative results are also presented for the proposed algorithm and the CDF formulation. Both the simulation and flight evaluations were carried out for a flight condition of Mach 0.90 and $30,000 \mathrm{ft}$, for a part power setting.

\section{Engine Description}

The engine used in this study is the Pratt \& Whitney F100 EMD low-bypass ratio, twin spool, afterbuming turbofan engine ${ }^{7}$ (Fig. 2). The engine is controlled by a DEEC, a full-authority digital electronic control system which performs the functions of the standard F100 engine hydromechanical, unified fuel control, and supervisory digital electronic engine control.

\section{Engine Models}

Pratt \& Whitney has developed a comprehensive nonlinear dynamic engine model, the state-of-the-ant propulsion program (SOAPP) model. This model is 
the best representation of the engine and predicts engine performance with minimal error over the full power range and flight envelope and for both steadystate and transicnt opcration. This nonlinear simulation is a high-fidelity model that represents each component in the engine and control but does not run in real time.

For real-time use, a set of lincarized SVMs were developed from the SOAPP model. To cover the entire flight envelope, 49 models were developed. The model is selected as a function of burner static pressure $(P B)$. These models compare well with the large scale nonlinear aerothermal model and actual engine test data, and they can be implemented efficiently in real time. Figure 3 shows a simulation model for the F100 engine based on the state variable formulation.

The SSM engine relationships and trim predictions (basepoints) are also derived from the SOAPP model. A two-dimensional table look-up scheduled on 7 values of $P B$ and 40 values of afterbumer total pressure $\left(P_{T_{6}}\right)$ is needed to represent the steady state information. Each SSM consists of a basepoint control vector, a basepoint output vector, and a sensitivity coefficient matrix which relates the changes in control positions to change in outputs.

The PSC algorithm requires the variables listed in Table 1, which are functions of the engine states and the input control variables. These variables include engine outputs which cannot be measured but are required to calculate performance measures of the engine. An additional set of variables, which are nonlinear functions of the unmeasured output variables, are listed in Table 2. These variables are used to predict both the engine performance and the constraints needed to develop optimal engine controllers.

\section{Kalman Filter Concepts}

The entire state vector of the system to be controlled is often assumed to be measurable. Most of the solutions to optimal control problems are obtaincd as a fecdback law implementable only if the entire state vector is available. In most complex systems the entire state vector cannot be measured, and a suitable approximation to the state vector must be determined and substituted into the control law. The system that produces, in deterministic setting, an approximation to the state vector is called an observer. ${ }^{8}$
Kalman and Bucy solved the optimal observer problem in a stochastic environment, and this solution has had a tremendous impact on optimal filtering theory. ${ }^{9}$ The Kalman filter represents the most widely applied and demonstrably useful result to emerge from the state variable approach of "modem control theory." 10

The system is

$$
\begin{aligned}
& \dot{x}=A x+B u+w_{1} \\
& y=C x+D u+w_{2}
\end{aligned}
$$

Where $A, B, C$, and $D$ are system matrices in state variable representation, $x$ is the state vector, $u$ is the control input vector, $y$ is the output vector, $w_{1}$ is the state excitation noise, and $w_{2}$ is the observation or measurement noise. Both $w_{1}$ and $w_{2}$ are white, uncorrelated Gaussian processes, with intensity $Q$ and $R$ respectively.

The observer is

$$
\dot{\hat{x}}=A \hat{x}+B u+K[y-C \hat{x}-D u]
$$

where $K$ is the Kalman filter gain.

The optimal observer problem is finding the matrix $K$ so as to minimize $E\left\{e^{\mathrm{T}} R e\right\}$, where

$$
e=x-\hat{x}
$$

and $R$ is a positive-definite symmetric weighting matrix. In this problem, $E$ is the expectation operator and $e$ is the state error vector. If $R$ is a positive-definite matrix, the optimal observer is called nonsingular. The Kalman filter is the solution to the nonsingular optimal observer previously outlined. The optimal observer problem is solved by choosing the gain matrix. ${ }^{11}$

$$
K=P C^{\mathrm{T}} R^{-1}
$$

where $P$ is the state error covariance matrix, $E\left[(x-\hat{x})(x-\hat{x})^{\mathrm{T}}\right]$, and is the solution to the matrix Riccati equation

$$
\dot{P}=A P+P A^{\mathrm{T}}+Q-P C^{\mathrm{T}} R^{-1} C P
$$

For a time invariant case, the steady state solution for $P$ is a constant matrix and is a unique nonnegative definite solution of the algebraic Riccati equation

$$
0=A P+P A^{\mathrm{T}}+Q-P C^{\mathrm{T}} R^{-1} C P
$$


Figure 4 shows a typical Kalman filter structure used to estimate states and outputs.

\section{Proposed Formulation}

In Kalman filter derivation, linear models for the system dynamics and measurement relation are assumed to be adcquate for developing optimal estimators. No model is perfect, and a linear model, in particular, is the result either of intentional approximation and simplification or of a lack of knowledge about the system being modeled. ${ }^{12}$ To account for degraded engine operation and modeling inaccuracies, the proposed formulation augments the output vector by adding a bias vector to represent the uncertain parameters. ${ }^{5}$ The dynamic equations can thus be expressed as

$$
\begin{aligned}
& \dot{x}=A x+B u+w_{1} \\
& y=C x+D u+b+w_{2}
\end{aligned}
$$

where $b$ is the bias vector. The bias vector is estimated by adjoining $b$ to $x$ and defining a new state vector, $z$

$$
z=\left[\begin{array}{c}
x \\
\cdots \\
b
\end{array}\right]
$$

with the condition

$$
\dot{b}=0
$$

The state equation can be rewritten as

$$
\begin{aligned}
& \dot{z}=A_{1} z+B_{1} u+G w_{1} \\
& y=C_{1} z+D u+w_{2}
\end{aligned}
$$

where

$$
\begin{array}{rlrl}
A_{1} & =\left[\begin{array}{ccc}
A & \vdots & 0 \\
\cdots & & \cdots \\
0 & \vdots & 0
\end{array}\right] & B_{1}=\left[\begin{array}{c}
B \\
\cdots \\
0
\end{array}\right] \\
C_{1}=\left[\begin{array}{lll}
C & \vdots & I
\end{array}\right] & G=\left[\begin{array}{c}
I \\
\cdots \\
0
\end{array}\right]
\end{array}
$$

If the estimate of $z$ is $\hat{z}$, where

$$
\hat{z}=\left[\begin{array}{c}
\hat{x} \\
\cdots \\
\hat{b}
\end{array}\right]
$$

then the Kalman filter estimate is given by

$$
\dot{\hat{z}}=A_{1} \hat{z}+B_{1} u+P C_{1}^{\mathrm{T}} R^{-1}\left[y-C_{1} \hat{z}-D u\right]
$$

where $P$ is the stcady state solution to the Riccati equation

$$
0=A_{1} P+P A_{1}^{\mathrm{T}}+G Q G^{\mathrm{T}}-P C_{1}^{\mathrm{T}} R^{-1} C_{1} P
$$

The auxiliary set of unmeasured output variables ( $\hat{y}_{a u x}$ ) are related to the engine states and control inputs through the algebraic equation

$$
\hat{y}_{a u x}=H z+F u
$$

Details of the state variable formulation for the F100 engine are presented in the appendix. The $\left(\hat{y}_{a u x}\right)$ outputs are listed in Table 1.

In spite of the mathematical formalism of the Kalman filter, enginecring insight and experience is required to develop an effective operational filter algorithm. A mathematical model of both the system structure and uncertainty is inherently embodied in the Kalman filter structure. The main design problem is attaining an adequate mathematical model upon which to base the filter. Even after selecting an appropriate model, the matrices $Q$ and $R$ can be difficult to determine. This is done by a process called "tuning" the Kalman filter, It is a trial and error procedure for determining which matrix values yicld the best estimation performance for that particular filter struclure.

The matrix $R$ was determined by analysis of flight data available for the F100 engine. The elements of matrix $Q$ were, however, selected by evaluating the performance of the Kalman filter by trial and error. Figure 5 shows the implementation process used to estimate the output variables for the F100 engine using the Kalman filter.

This proposed formulation estimates unmeasured output variables by explicitly modeling the effects of off-nominal engine behavior as biases on the measurable output variables.

\section{Results}

The proposed estimation algorithm was developed and cvaluated for a Mach 0.90 and 30,000 ft flight condition. The algorithm was evaluated by a comparison with SOAPP simulation results and also by application to flight data. The flight data results were compared with the CDF formulation results for the same data.

\section{Simulation Evaluation}

The SOAPP simulation evaluations consisted of estimating the desired variables using both a nominal and 
a degraded engine. In cach case, the power lever angle (PLA) was held to $37^{\circ}$ for $15 \mathrm{sec}$ and then stepped up to $43^{\circ}$ and held constant for the remainder of the run.

Measured outputs were obtained from the SOAPP simulation and were corrupted with noise, as shown in Table 3. These are typical values obtained from flight data. The measurements with noise and the values of the control variables were entered into the estimation algorithm and the desired estimates were obtained. The Kalman filter state vector, a perturbation of the steady statc conditions, was initialized to zero for all states.

The algorithm needed to generate consistent state estimates which were robust with respect to the measurement covariance matrix $Q$ (the only variable selected by trial and crror). An important aspect of the development is determining unmeasured output vector, $\hat{y}_{a u x}$. Inconsistent estimates of the states would give different values of $\hat{y}_{a u x}$ for different values of $Q$ when applied to the same data.

The state vector estimates converged to the same value for different values of $Q$. This was evaluated for values of $Q=\mathrm{I}$ and $\mathrm{Q}=10 \mathrm{I}$. The difference in the estimated states for $Q=\mathrm{I}$ and $Q=10 \mathrm{I}$, for a nominal engine, is shown in Fig. 6. This figure shows that the state estimates converge to the same value and the effect of change in $Q$ on the steady-state response is minimal.

The five measured output variables obtained from the SOAPP for a nominal engine were compared with the estimates of these variables obtained from the filter (Fig. 7(a)). The prediction values subtracted from the simulated measurements were held constant throughout the run. These values were the same as the simulated measurements at the beginning of the run, accounting for the excellent comparison over the initial interval. The Kalman filter was not updated in this evaluation, so the comparisons indicate that the model is quite robust. The comparisons are very good in spite of the large change in the operating conditions. The CDF based formulation would have used five different models for the $P B$ change of this mancuver.

Figure 7(b) shows the measurement bias estimates. As expected, they are nearly zero until the PLA is increased. As the engine attains a new operating condition, the bias parameters increase to levels which account for the efrects not modeled in the SVM.
To assess the condition when significant differences exist between the measured data and the predicted data, the following nominal biases were added to the simulated light data: $\Delta N_{1}$ (fan rotor speed) $=$ 50.0, $\Delta N_{2}$ (core rotor specd) $=50.0, \Delta P B=2.0$, $\Delta T_{T_{4.5}}$ (low turbine inlet total temperature) $=30.0$, and $\Delta P_{T_{6}}=0.5$. The results of this evaluation (Fig. 8(a)) show that the tracking of the five measurements is again very good. The final values of the bias estimates (Fig. 8(b)) are the sum of biases estimated in Fig. 7(b) and the biases placed on the simulated measurements as previously listed.

In Fig. 9, estimates of the unmeasured output variables $\left(\hat{y}_{a u x}\right)$ are compared with the actual values obtained from the SOAPP. The estimates show good tracking of the simulation values.

Simulation evaluations were then carried out for a degraded engine by simultancously introducing the following deteriorations: (a) high turbine efficiency is 2.5 percent below nominal, (b) low turbine efficiency is 2.5 percent below nominal, (c) compressor airflow deviation is $1 \mathrm{lb} / \mathrm{sec}$ less than nominal, and (d) the fan airflow deviation is $5 \mathrm{lb} / \mathrm{sec}$ less than nominal.

The results for the simulated degraded engine are presented in Fig. 10. These results are similar to the results of Fig. 7 and demonstrate the adaptability and robustness of the proposed estimator to degraded engine performance. Again, the Kalman filter was not updated during the evaluation and the predicted constant values subtracted from the simulated data were the same as those for an engine that was not degraded.

\section{Flight Data Evaluation}

The Kalman filter formulation was also evaluated on flight data obtained on the NASA F-15 research aircraft. The flight data was obtained at Mach 0.90, an altitude of $30,000 \mathrm{ft}$, and a PLA of $43.5^{\circ}$. The time history of the test data (Fig. 11) starts with no bleed air bcing extracted from the test engine. Approximately $40 \mathrm{sec}$ into the run, the pilot manually changed the bleed switch to extract all the aircraft bleed air requirements from the test engine. This mancuver was designed to simulate a change in engine operating efficiency. The engine control system increased fuel flow $\left(W_{F}\right)$ to maintain the scheduled fan speed, resulting in an increase in $T_{T_{4} 5}$. After holding this blecd condition for approximately $70 \mathrm{sec}$, the bleed was again switched back to the initial no bleed air condition. 
The Kalman filter estimation results are shown in Fig. 12. Figure 12(a) shows that the filter tracks the flight measurements accurately. Initial discrepancies occur because the bias estimates start at zero; howcver, this startup transient is bricf, with good tracking occurring in approximately $20 \mathrm{sec}$. Although the tracking quality is slightly worse at the time the blecd switching occurs, the filter rapidly adapts to the simulated change in engine efficiency. The bias estimates, shown in Fig. 12(b), converge rapidly to steady-state values as the engine state is changed from one condition to another. The initial startup transient could be minimized by initializing the bias estimates with the actual values of the biases for the given flight condition.

Figure 13 shows the results from the proposed formulation compared with the corresponding results from the CDF formulation. The results were obtained using the flight data shown in Fig. 11. The results show that the performance obtained by the proposed method compares favorably with the CDF procedure. A significantly improved startup transient performance is evident. Figure 14 presents similar comparisons for the estimates of normally unmeasured output variables. Figure 14(a) shows the estimate of compressor inlet total temperature $\left(T_{T_{2.5}}\right)$ and the measured values. The superiority of the proposed formulation is clearly cvident, if the measurement of $T_{T_{2.5}}$ is considered reliablc. Figure 14(b) shows the comparative estimates of corrected fan airflow $\left(W C_{F A N}\right)$. The values are comparable, with better transient performance for the proposed formulation.

\section{Concluding Remarks}

An approach has been proposed to estimate the unmeasured or auxiliary output variables of a turbofan F100 engine by using Kalman filter concepts. The approach is based on explicitly modeling the effects of off-nominal engine bchavior as biases on the measured output variables. Results are presented for estimates of the output variables and are compared with values obtained from detailed nonlinear simulation of the engine. The evaluation was carried out for both a nominal engine and an engine in which intentional deterioration was introduced. The proposed filter was also cvaluated for output estimation using actual F-15 flight data.
The formulation is robust with respect to the value of statc covariance matrix $Q$. A critical component of the performance secking control (PSC) problem for the F100 engine is determining consistent values for auxiliary output variables. Consistent estimates for the states were obtained for different values of $Q$ and thus consistent estimates of the auxiliary output variables are ensured.

The proposed estimation algorithm was able to accurately predict the values of the output variables for the simulation studies for both nominal and degraded engine conditions. The proposed algorithm has been validated by comparing its estimates with the values from the detailed nonlinear simulation, and it has performed well on flight data. A comparative study of the proposed algorithm results with component deviation factors (CDF) results gave additional proof of the validity of the concept. Unlike the CDF method, the proposed algorithm does not require detailed modeling of the engine degradation process. This formulation has a wide range of application because it is not restricted or tailored to the particular application described in this paper.

\section{References}

${ }^{1}$ Tich, Eric J., Shaw, Peter D., Berg, Donald F., Adhibatla, Shrider, Swan, Jerry A., and Skira, Charles A., "Performance Secking Control for Cruise Optimization in Fighter Aircraft," AIAA-87-1929, June 1987.

${ }^{2}$ Burcham, Frank W., Jr., Gilyard, Glenn B., and Myers, Lawrence P., "Propulsion System/Flight Control Integration and Technology Transition," AIAA90-2280, July 1990.

${ }^{3}$ Luppold, R.H., Gallops, G.W., Kerr, L.J., and Roman, J.R., "Estimating In-Flight Engine Performance Variations Using Kalman Filter Concepts," AIAA-892584, July 1989.

${ }^{4}$ Bcrg, D.F., Swan, J.A., Ahdibatlar, S., Shaw, P.D., and Tich, E.J., "Performance Secking Control Volume 1: Final Report," AFWAL-TR-88-2067, Oct. 1989.

${ }^{5}$ Fricdland, Bemard, "Treatment of Bias in Recursive Filtcring," IEEE Transactions on Automatic Control, vol. AC-14, no. 4, Aug. 1969, pp. 359-367.

${ }^{6}$ Maine, Trindel A., Gilyard, Glenn B., and Lambert, Heather H., "A Preliminary Evaluation of an 
F100 Engine Parameter Estimation Process Using Flight Data," AIAA-90-1921, July 1990.

${ }^{7}$ Myers, Lawrence P., and Burcham, Frank W., Jr., "Preliminary Flight Test Results of the F100 EMD Engine in an F-15 Airplane," NASA TM-85902, 1984.

${ }^{8}$ Luenberger, David G., "An Introduction to Obscrvers," IEEE Transactions on Automatic Control, vol. AC-16, no. 6, Dec. 1971, pp. 596-602.

${ }^{9}$ Kalman, R.E., and Bucy, R.S., "New Results in Lincar Filtering and Prediction Theory," J. Basic En- gineering Transactions ASME, Ser. D., March 1961, no. 83, pp. 95-108.

${ }^{10}$ Sorenson, Harold W., "Kalman Filtering: Theory and Application," IEEE Press, New York, 1985.

${ }^{11}$ Kwakernaak, Huibert, and Sivan, Raphael, Linear Optimal Control Systems, Wiley InterScience, New York, 1972.

${ }^{12}$ Maybeck, Peter S., Stochastic Models, Estimation and Control, vol. 2, Academic Press, New York, 1982. 


\section{Appendix-State Variable Auxiliary Output Estimation Formulation for an F100 Engine}

For the system being considered, the complete state variable model is

$$
\begin{aligned}
& \delta \dot{z}=A_{1} \delta z+B_{1} \delta u+G w_{1} \\
& \delta y=C_{1} \delta z+D \delta u+w_{2}
\end{aligned}
$$

where 1 indicates augmented system matrices, and

$$
\delta z=\left|\begin{array}{c}
\delta N_{1} \\
\delta N_{2} \\
\delta T M T \\
N_{1_{b}} \\
N_{2_{b}} \\
P_{T_{b}} \\
P B \\
T_{T_{4.5}}
\end{array}\right| \delta u=\left|\begin{array}{c}
\delta W_{F} \\
\delta A_{J} \\
\delta C I V V \\
\delta R C V V
\end{array}\right| \delta y=\left|\begin{array}{c}
\delta N_{1} \\
\delta N_{2} \\
\delta P_{T_{b}} \\
\delta P B \\
\delta T_{T_{4.5}}
\end{array}\right|
$$

where $T M T$ is the turbine metal temperature, $b$ denotes the output bias term, CIVV is the fan inlet guide vane angle, $R C V V$ is the compressor stator vane angle, and

$$
\begin{array}{rlrl}
A_{1} & =\left[\begin{array}{ccc}
A & \vdots & 0 \\
\cdots & & \cdots \\
0 & \vdots & 0
\end{array}\right] & B_{1}=\left[\begin{array}{c}
B \\
\cdots \\
0
\end{array}\right] \\
C_{1}=\left[\begin{array}{ll}
C \vdots I & I
\end{array}\right. & G=\left[\begin{array}{c}
I \\
\cdots \\
0
\end{array}\right]
\end{array}
$$

where $A, B, C$, and $D$ are constant perturbation matrices, numcrically derived from the SOAPP, $w_{1}$ is the state noise with covariance $Q$, and $w_{2}$ is the mcasurement noise with covariance $R$. The elements of $R$ are obtained from a priori night data, while those of $Q$ are sclected by trial and error.

The auxiliary set of unmeasured output variables $\left(\hat{y}_{\text {aux }}\right)$ listed in Table 1 , is given by

$$
\hat{y}_{a u x}=H \delta z+F \delta u+y_{t}
$$

where

$$
H=\left[\begin{array}{lll}
H_{1} & \vdots & H_{2}
\end{array}\right]
$$

and $H_{2}$ reflects the effect of estimated biases and its elements are derived from the SVM, $H_{1}$ and $F$ are perturbation matrices derived from the SOAPP, and $y_{t}$ is the vector of predicted trim values for the auxiliary output variables, which is obtained from the SVM. 
Table 1. Linear auxiliary output variables, PSC algorithm requirements.

\begin{tabular}{ll}
\hline \hline$P_{T_{2.5}}$ & compressor inlet total pressure \\
$P B$ & bumer static pressure \\
$P_{T_{6}}$ & afterbumer inlet total pressure \\
$T_{T_{2.5}}$ & compressor inlet total temperature \\
$T_{T_{3}}$ & bumer inlet total temperature \\
$T_{T_{4}}$ & burner exit total temperature \\
$T_{T_{4.5}}$ & low turbine inlet total temperature \\
$T_{T_{6}}$ & afterbumer inlet total temperature \\
$W C_{F A N}$ & corrected fan air flow \\
$W C_{H P C}$ & corrected compressor air flow \\
\hline \hline
\end{tabular}

Table 2. Nonlinear engine variables.

\begin{tabular}{ll}
\hline \hline$D_{N O Z}$ & nozzle drag \\
$D_{R A M}$ & ram drag \\
$F_{G}$ & gross thrust \\
$F_{N P}$ & net propulsive force \\
$P_{T_{7}}$ & nozzle throat total pressure \\
$S M_{F}$ & fan stall margin \\
$S M_{H C}$ & high compressor stall margin \\
$T_{T_{7}}$ & nozzle throat total temperaturc \\
\hline \hline
\end{tabular}

Table 3. Mcasurement noise statistics.

\begin{tabular}{lc}
\hline \hline Parameter & Standard deviation \\
\hline$N_{1}$ & $7 \mathrm{pm}$ \\
$N_{2}$ & $7 \mathrm{rpm}$ \\
$P_{T_{6}}$ & $0.3 \mathrm{lb} / \mathrm{in}$ \\
$P_{T_{4}}$ & $0.6 \mathrm{lb} / \mathrm{in}$ \\
$T_{T_{45}}$ & $4^{\circ} \mathrm{R}$ \\
\hline \hline
\end{tabular}

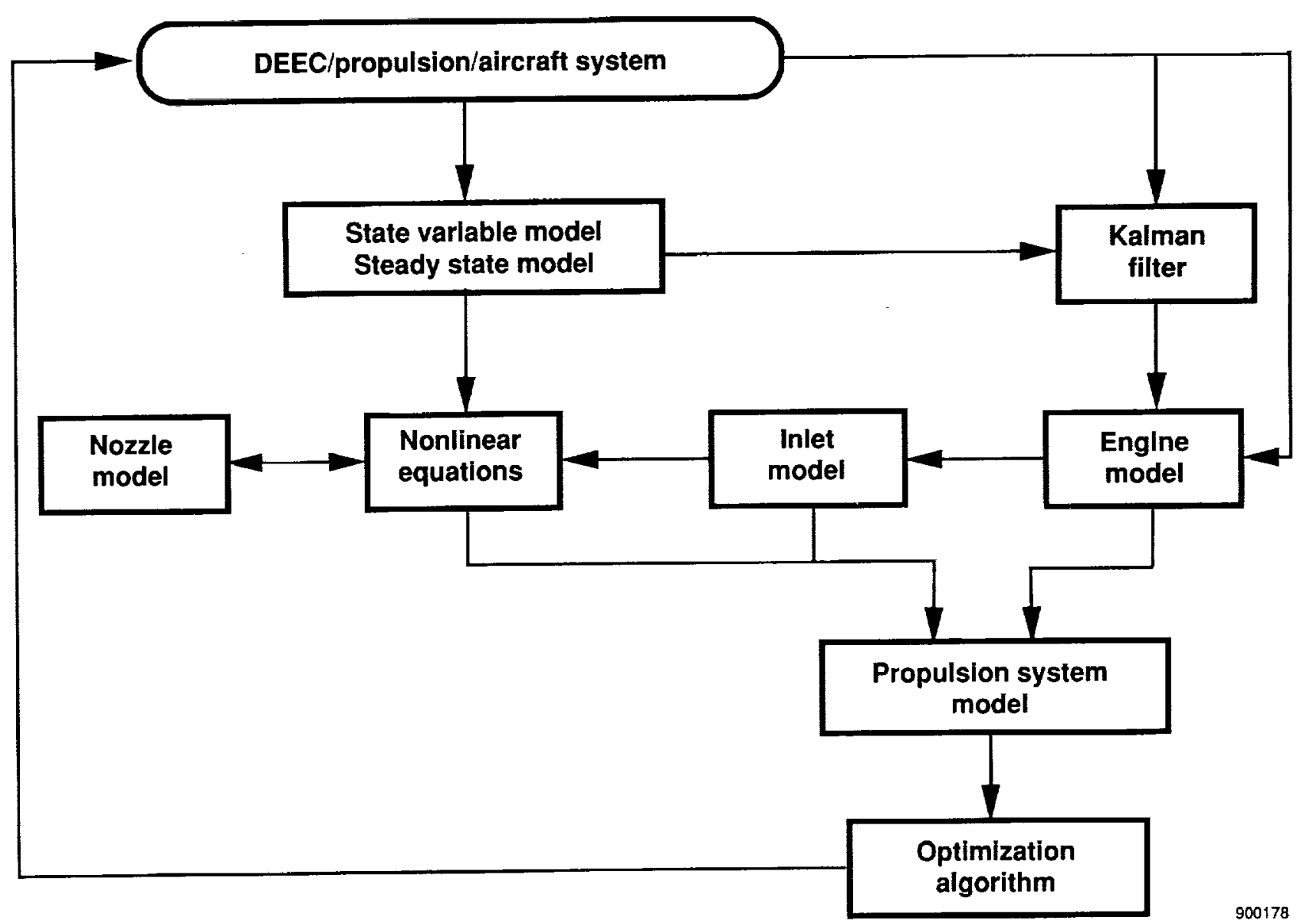

Fig. 1 The performance secking control adaptive control system. 
* DEEC sensors

t Instrumentation

₹ Calculated parameter

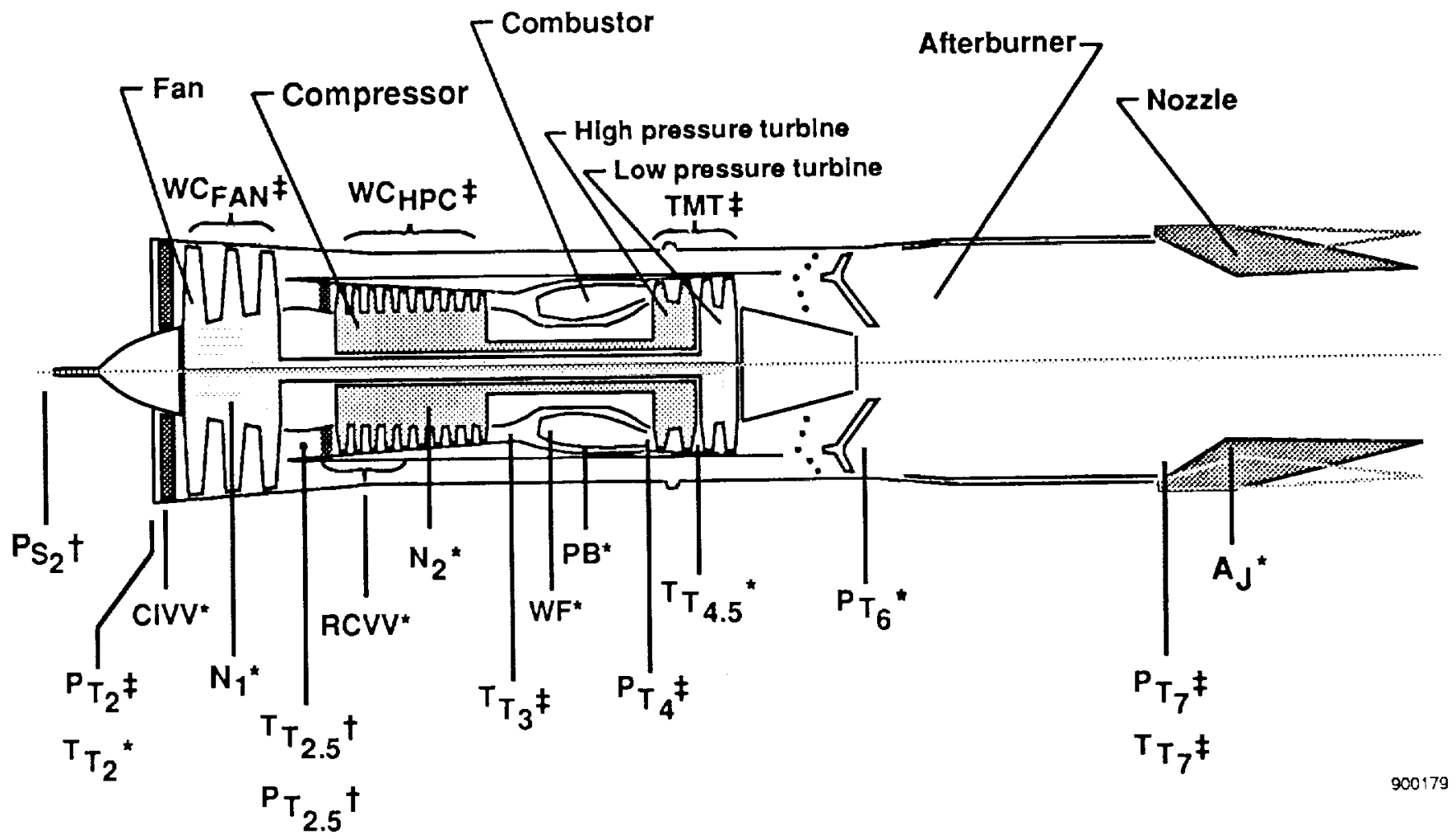

Fig. 2 The F100 engine and sensor locations. 


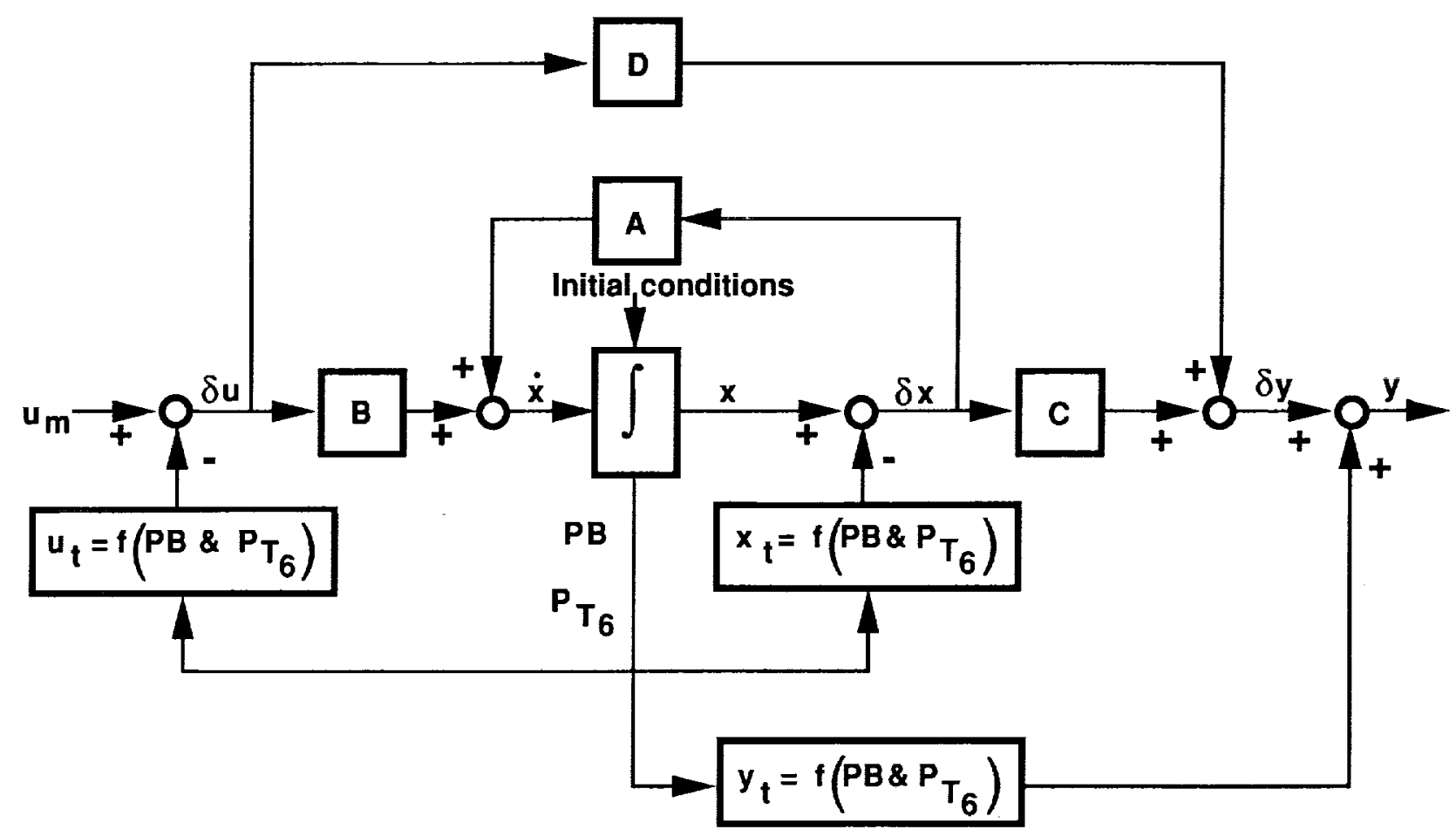

$x$ vector

u vector

y vector

$\left[\begin{array}{c}\text { Fan rotor speed, } \mathbf{N}_{1} \\ \text { Core rotor speed, } \mathbf{N}_{2} \\ \text { Turbine metal } \\ \text { temperature, TMT }\end{array}\right]$

$\left.\begin{array}{c}\text { Main burner fuel } \\ \text { flow, } \mathbf{W}_{\mathbf{F}} \\ \text { Nozzle area, } \mathbf{A}_{\mathrm{J}} \\ \text { Fan inlet guide } \\ \text { vane angle, CIVV } \\ \text { Compressor stator } \\ \text { vane angle, RCVV }\end{array}\right]$

Fig. 3 The F100 engine simulation based on the state variable model. 


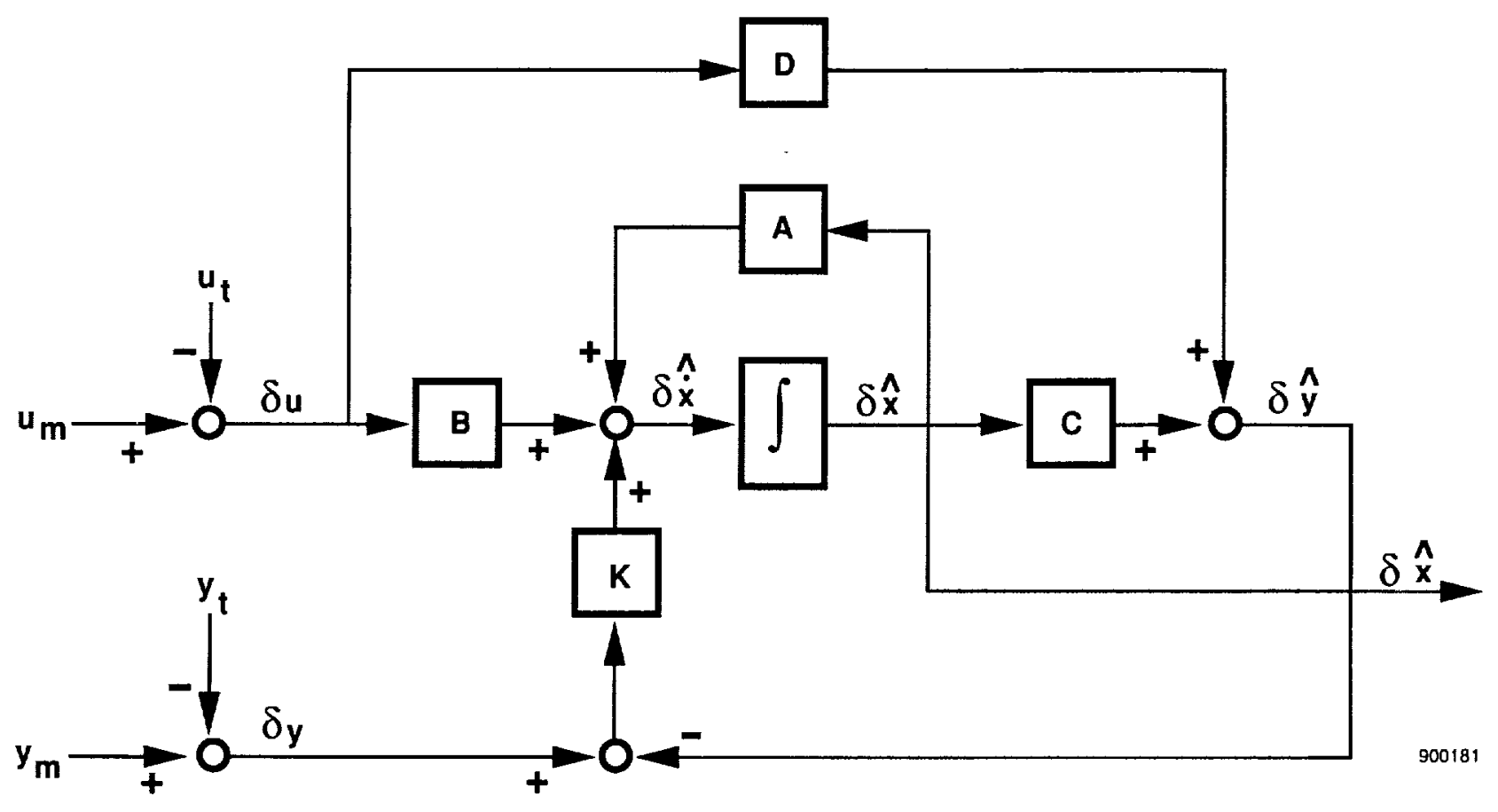

Fig. 4 The Kalman filter structure.

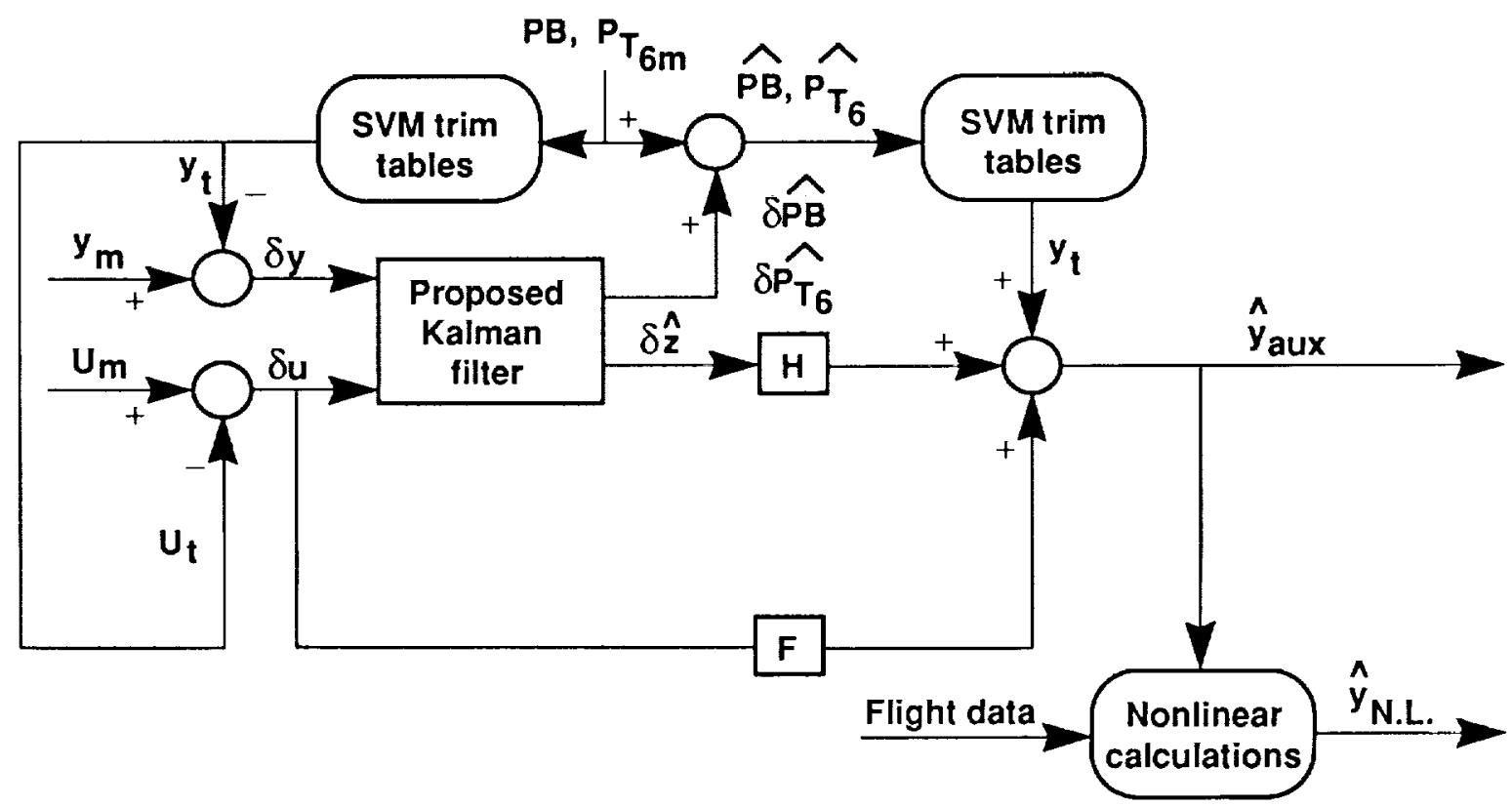

$$
\begin{aligned}
& \hat{Z}=\left[N_{1}, N_{2}, T M T, N_{1 b}, N_{2 b}, P_{T_{6 b}}, P_{b}, T_{T_{4.5 b}}\right] \\
& u=\left[W_{F}, A_{J}, C I V V, R C V V\right] \\
& y=\left[N_{1}, N_{2}, P B, P_{T_{6}}, T_{T_{4.5}}\right]^{\prime} \\
& \hat{y}_{\text {aux }}=\left[\mathrm{P}_{\mathrm{T}_{2.5}}, \mathrm{~T}_{\mathrm{T}_{2.5}}, \mathrm{~T}_{\mathrm{T}_{3}}, \mathrm{~T}_{\mathrm{T}_{4}}, \mathrm{~T}_{\mathrm{T}_{6}}, W \mathrm{C}_{\mathrm{FAN}}, \mathrm{WC} \mathrm{CPCZ}_{\mathrm{HPC}}\right] \text {, } \\
& \hat{y}_{N . L .}=\left[S M_{F}, S M_{H C}, D_{R A M}, D_{N O Z}, F_{N P}, F_{G}, T_{T_{7}}, P_{T_{7}}\right] \text { ' }
\end{aligned}
$$

Fig. 5 Modificd estimation process using the proposed Kalman filter. 

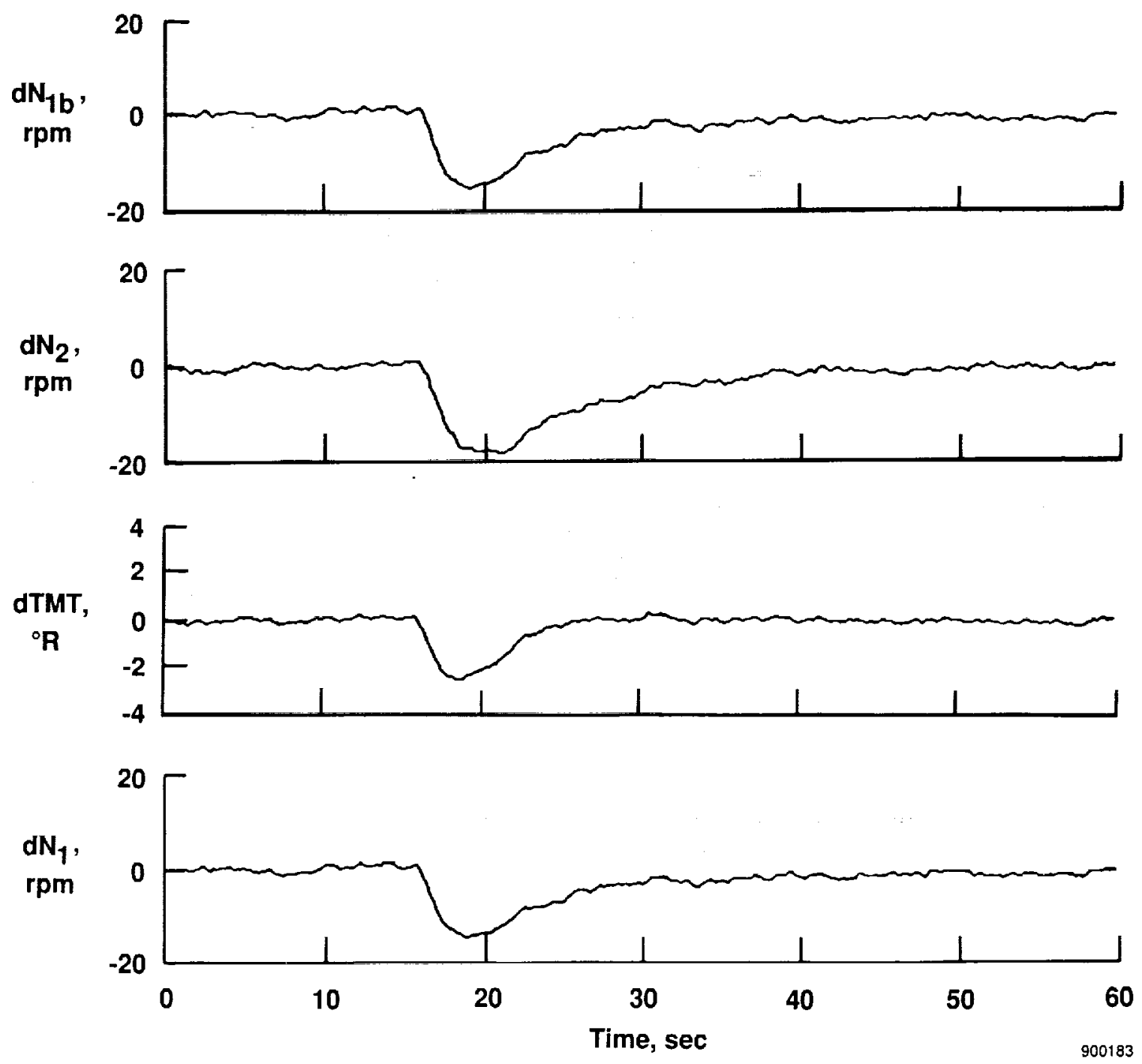

Fig. 6 The F100 engine simulation state estimates for a nominal cngine at $Q=\mathrm{I}$ and $Q=10 \mathrm{I}$, PLA increased from $37^{\circ}$ to $43^{\circ}$ at $15 \mathrm{sec}$. 

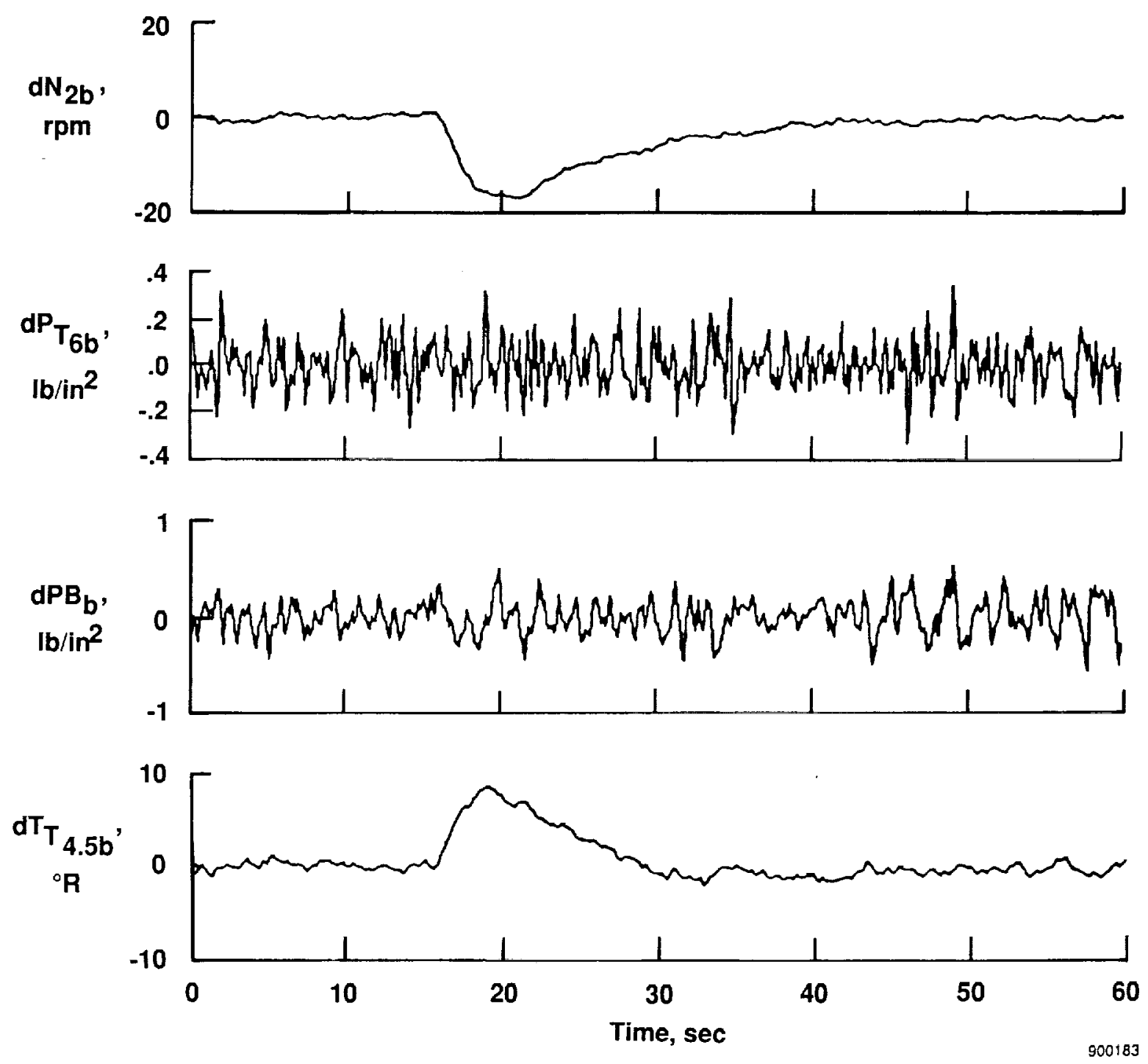

Fig. 6 Concluded. 

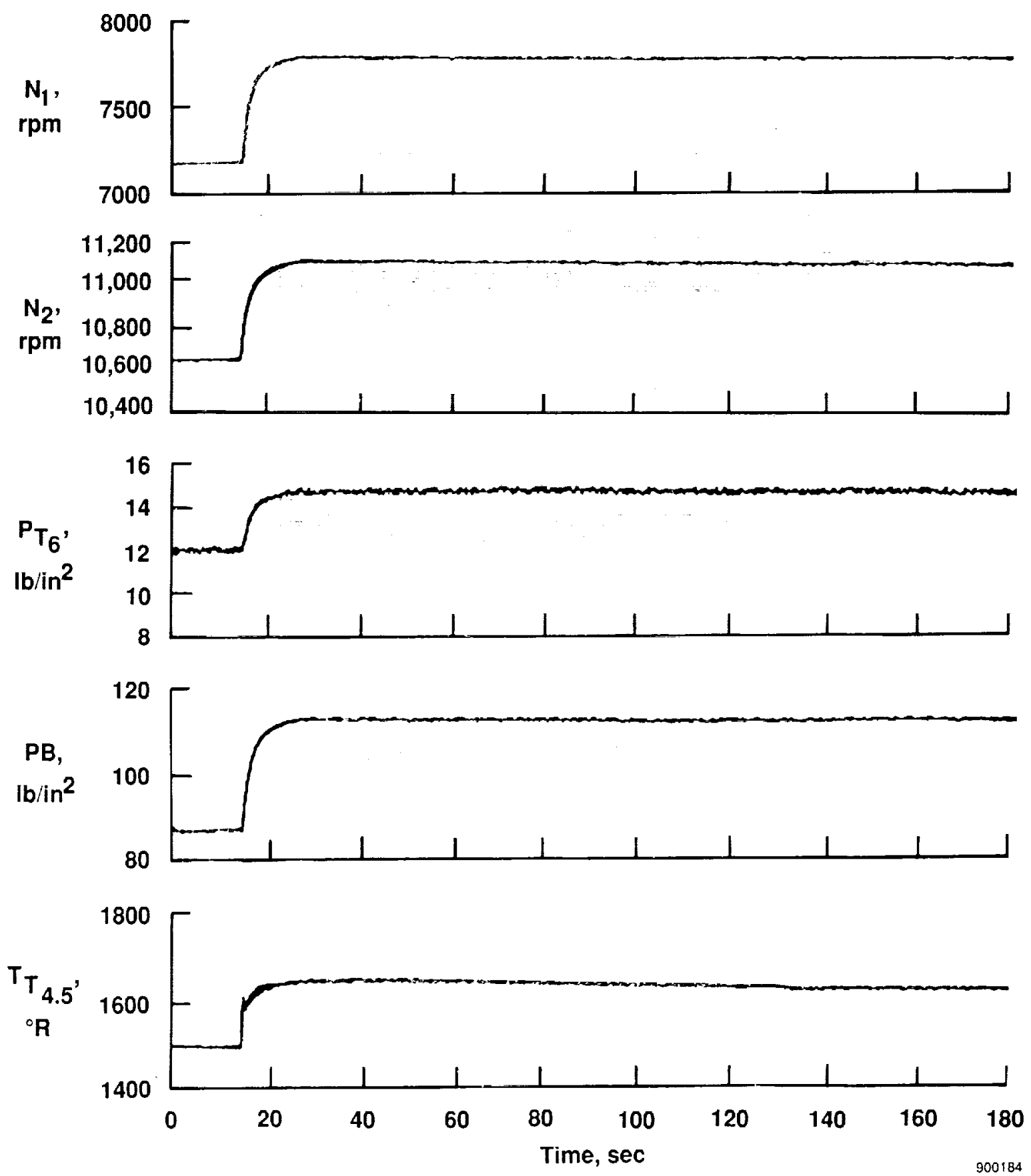

(a) Measured and estimated engine outputs.

Fig. 7 The F 100 engine simulation parameters for a nominal engine, with PLA increased from $37^{\circ}$ to $43^{\circ}$ at 15 sec. 

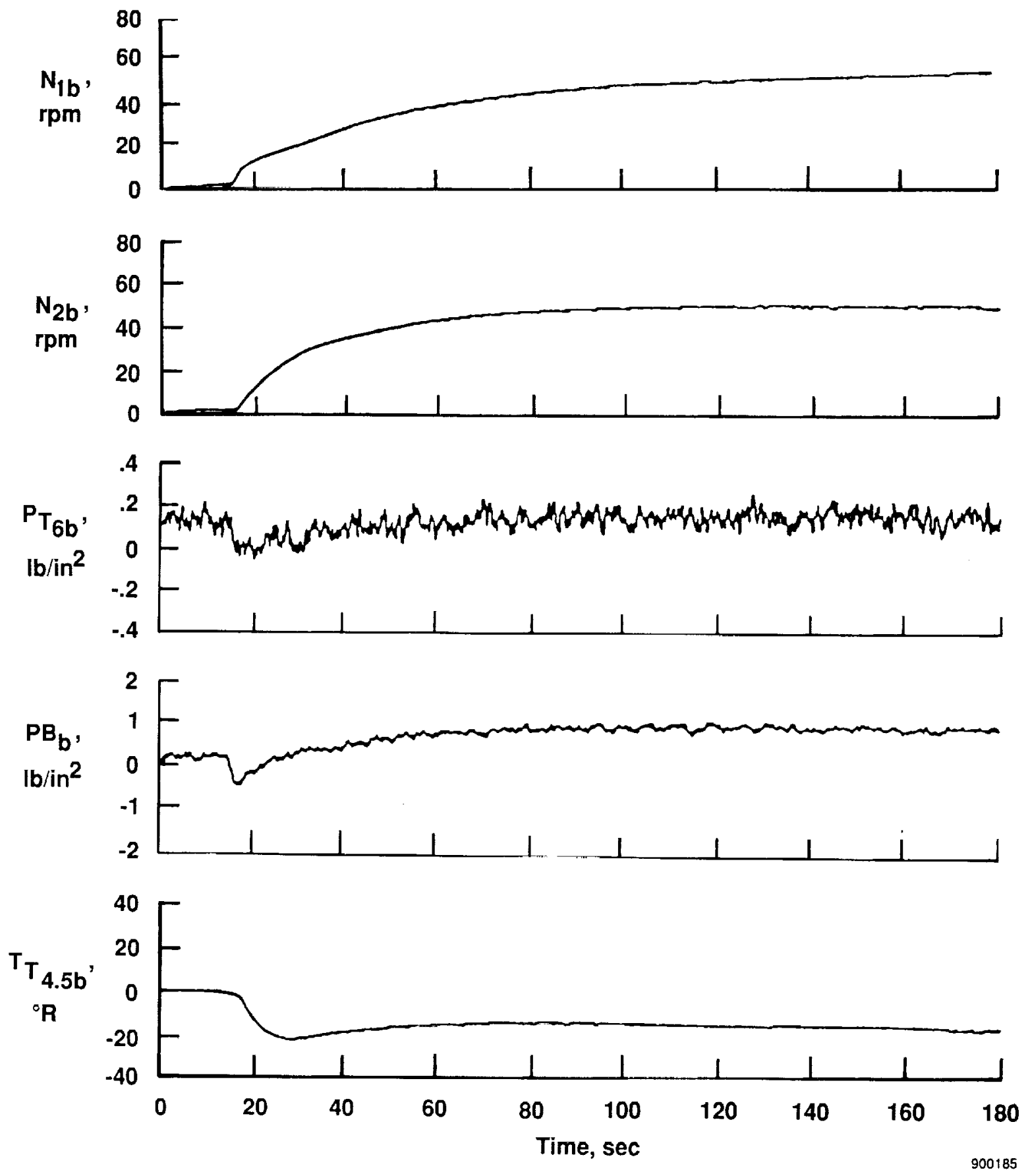

(b) Bias cstimates.

Fig. 7 Concluded. 

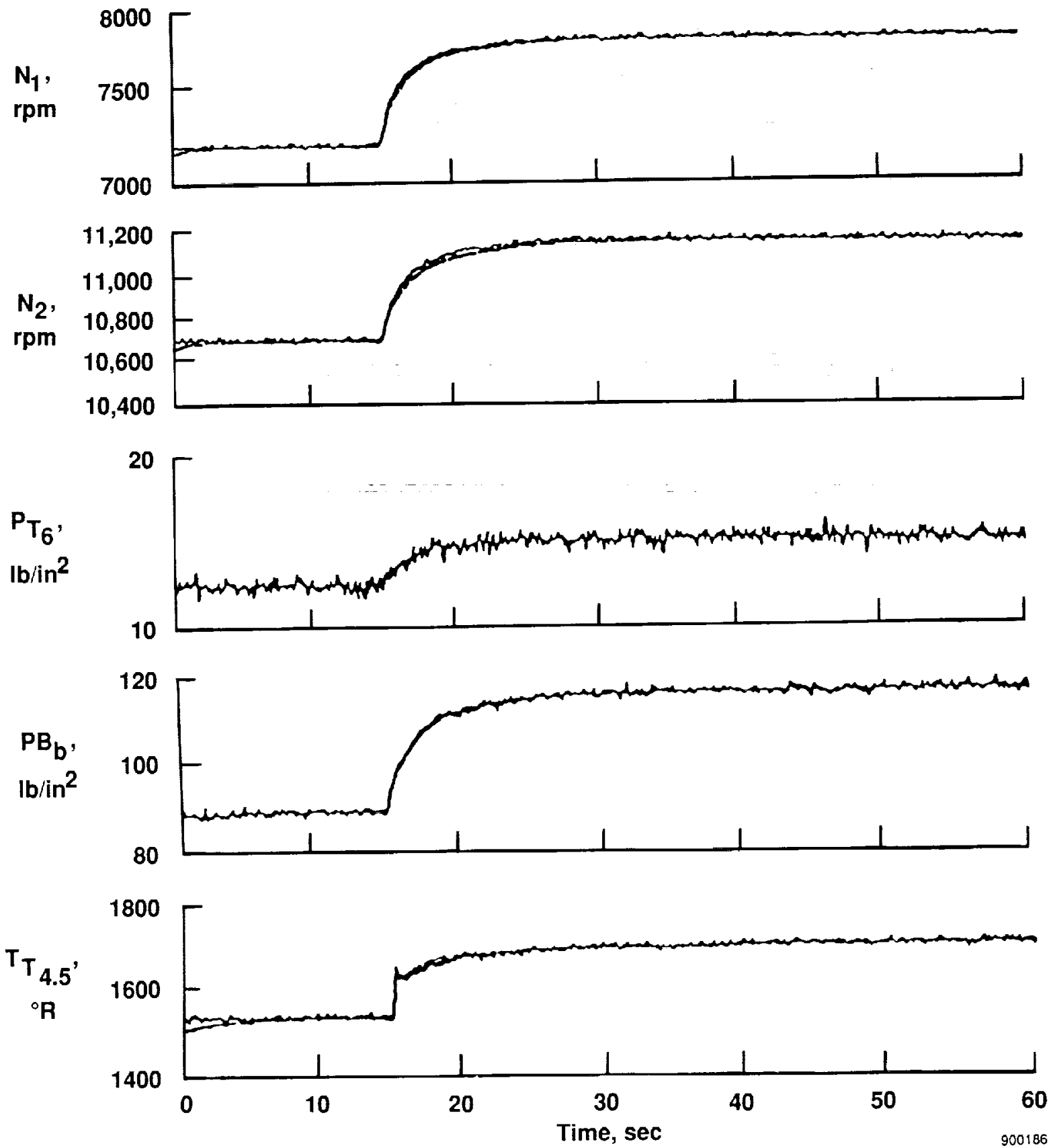

(a) Mcasured and estimated engine outputs.

Fig. 8 The F100 engine simulation parameicr estimates with biased measurements for a nominal engine, with PLA increased from $37^{\circ}$ to $43^{\circ}$ at 15 scc. 

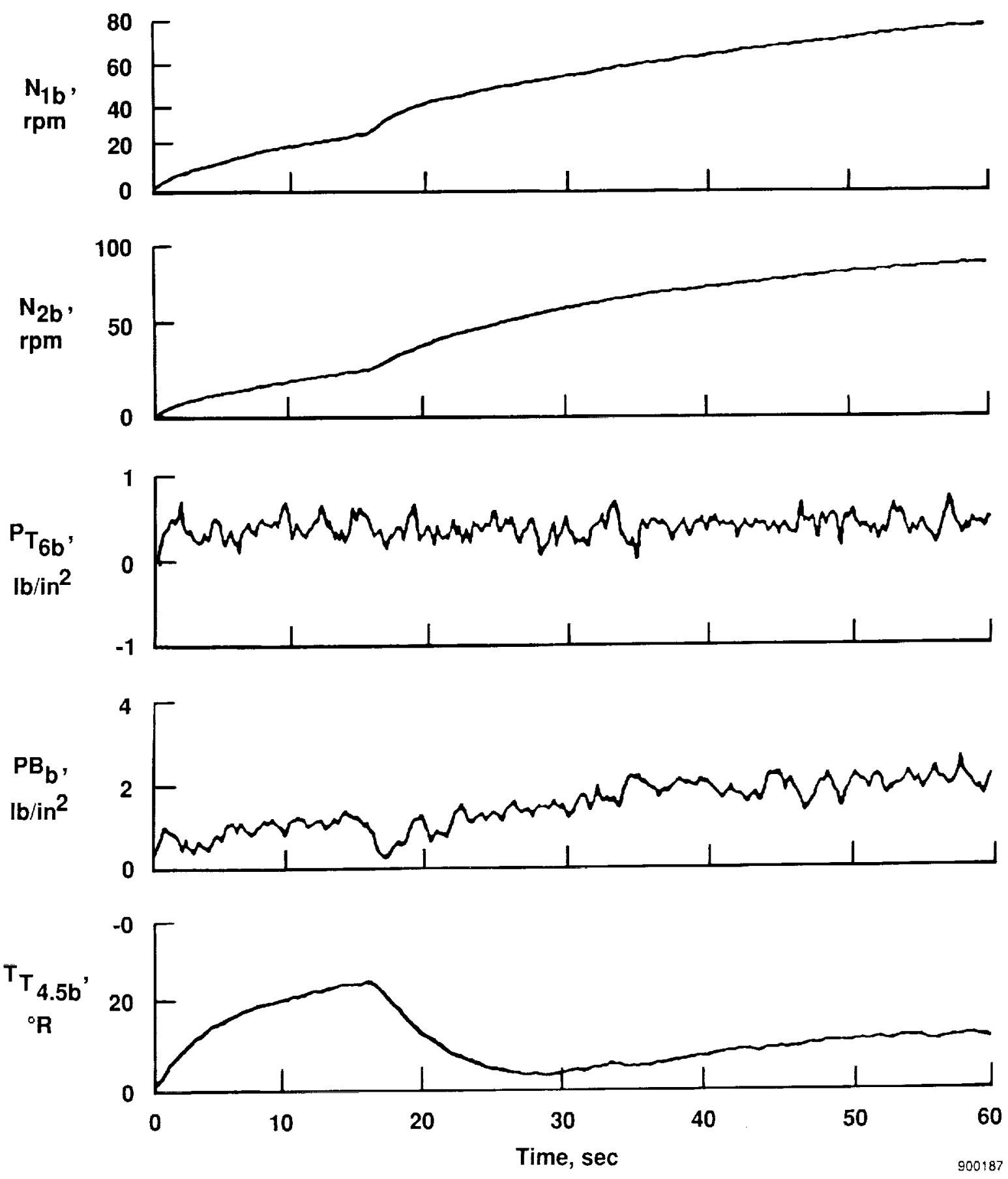

(b) Bias estimales.

Fig. 8 Concluded. 
— SOAPP

Estimated
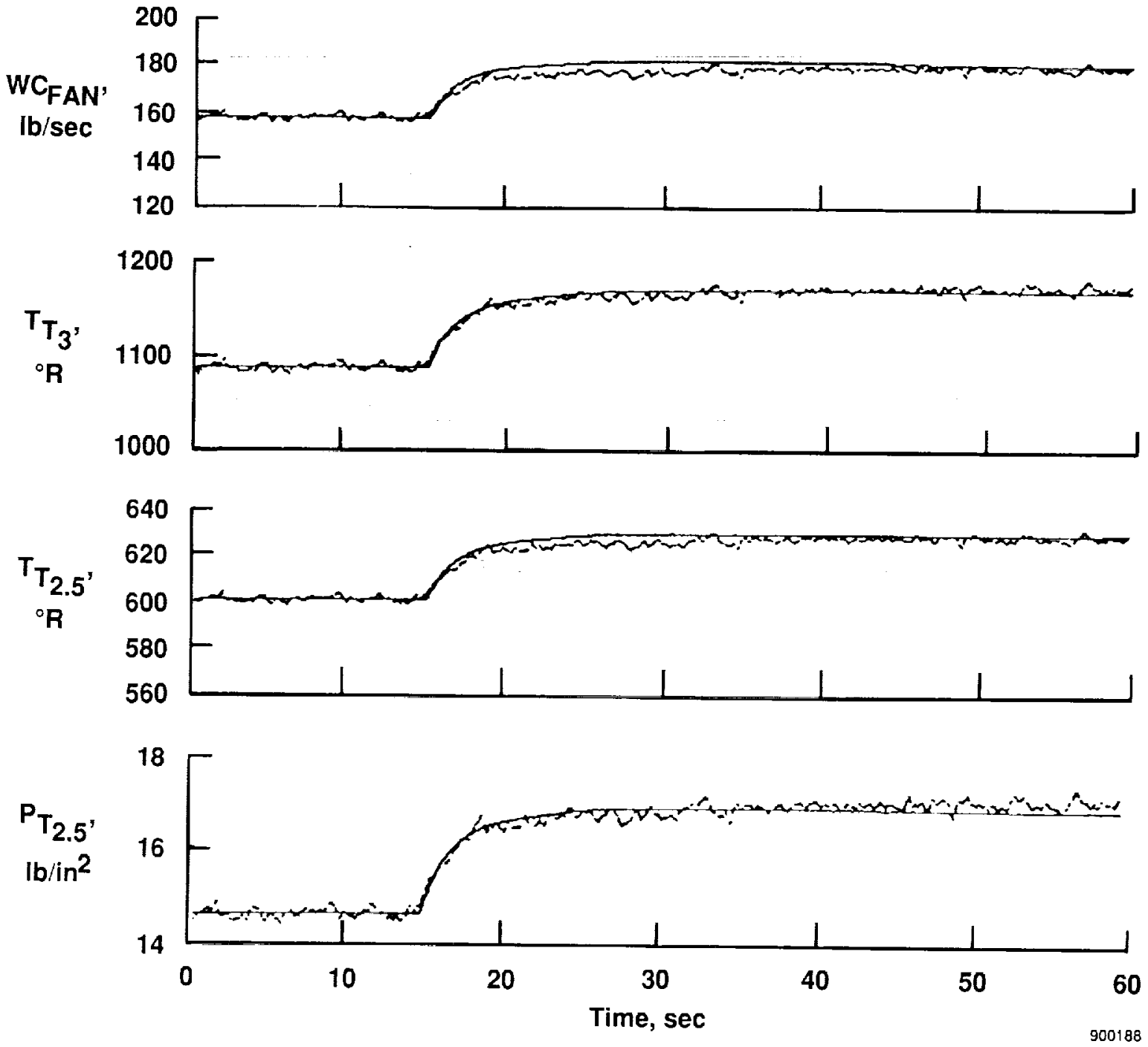

Fig. 9 The F100 cngine simulation auxiliary outpul estimates for a nominal engine, with PLA increased from $37^{\circ}$ to $43^{\circ}$ at $15 \mathrm{sec}$. 

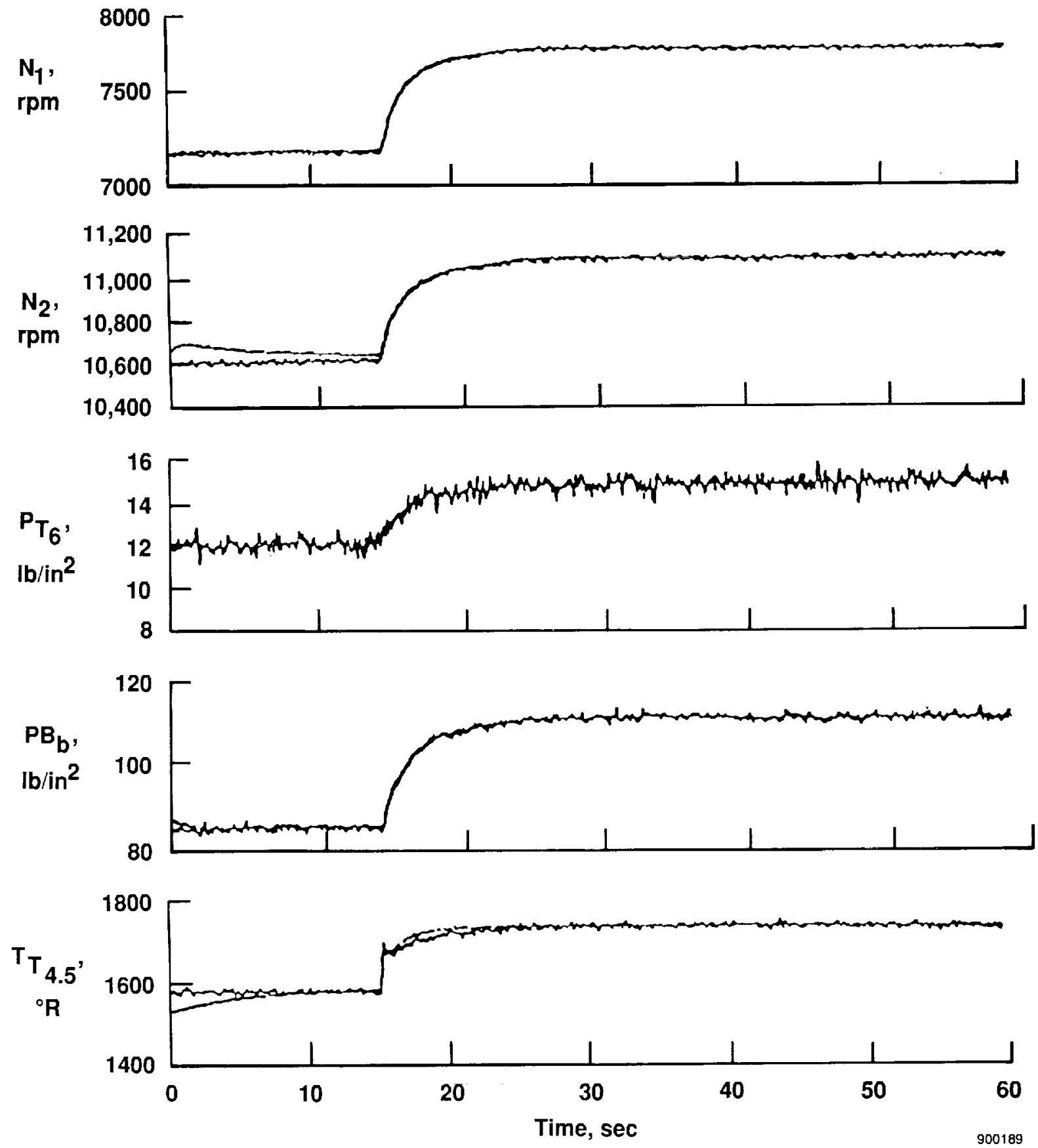

(a) Engine output estimates.

Fig. 10 The F100 engine simulation parameter estimates for a deteriorated engine, with PLA increased from $37^{\circ}$ to $43^{\circ}$ at $15 \mathrm{scc}$. 

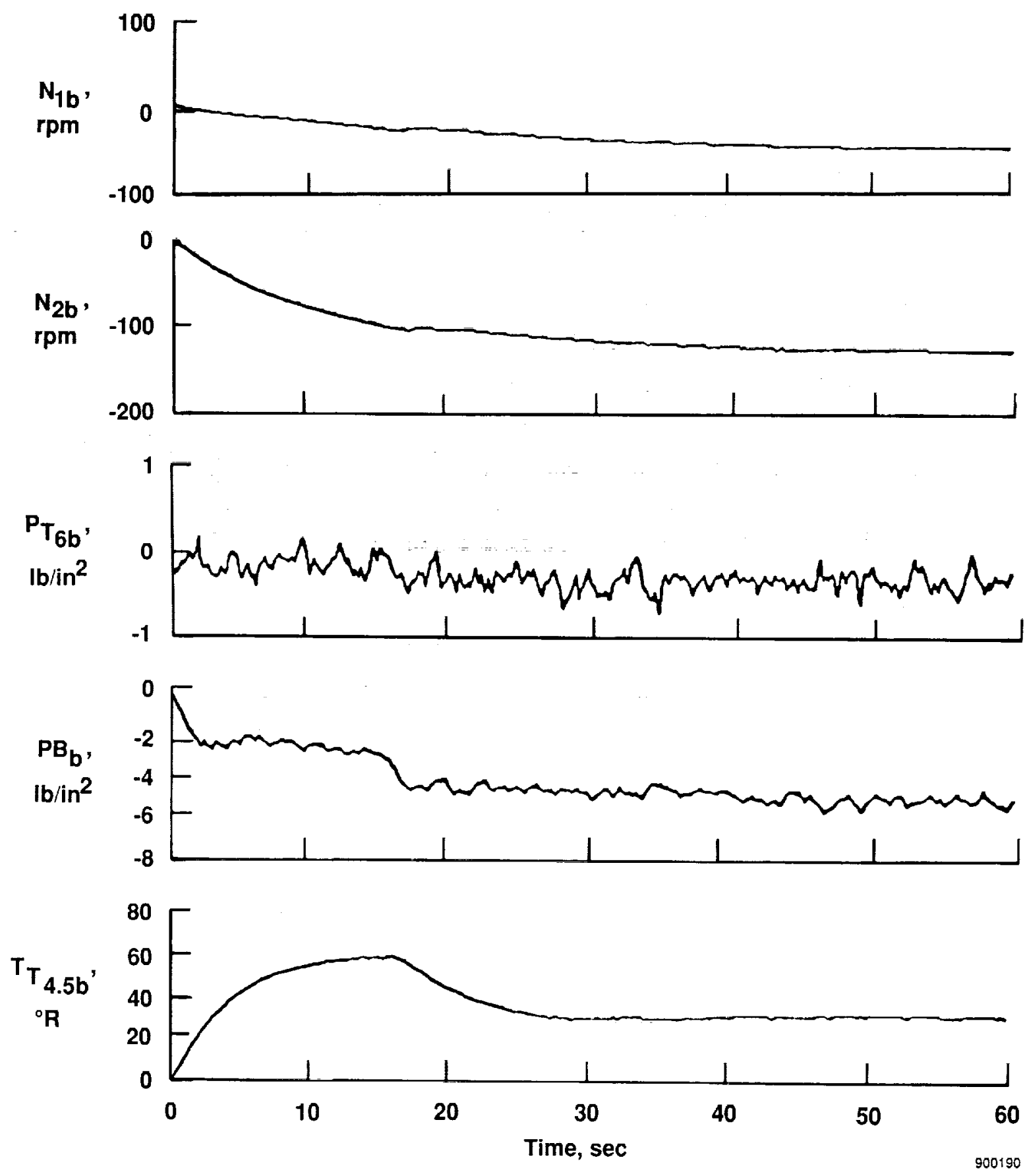

(b) Bias estimates.

Fig. 10 Concluded. 

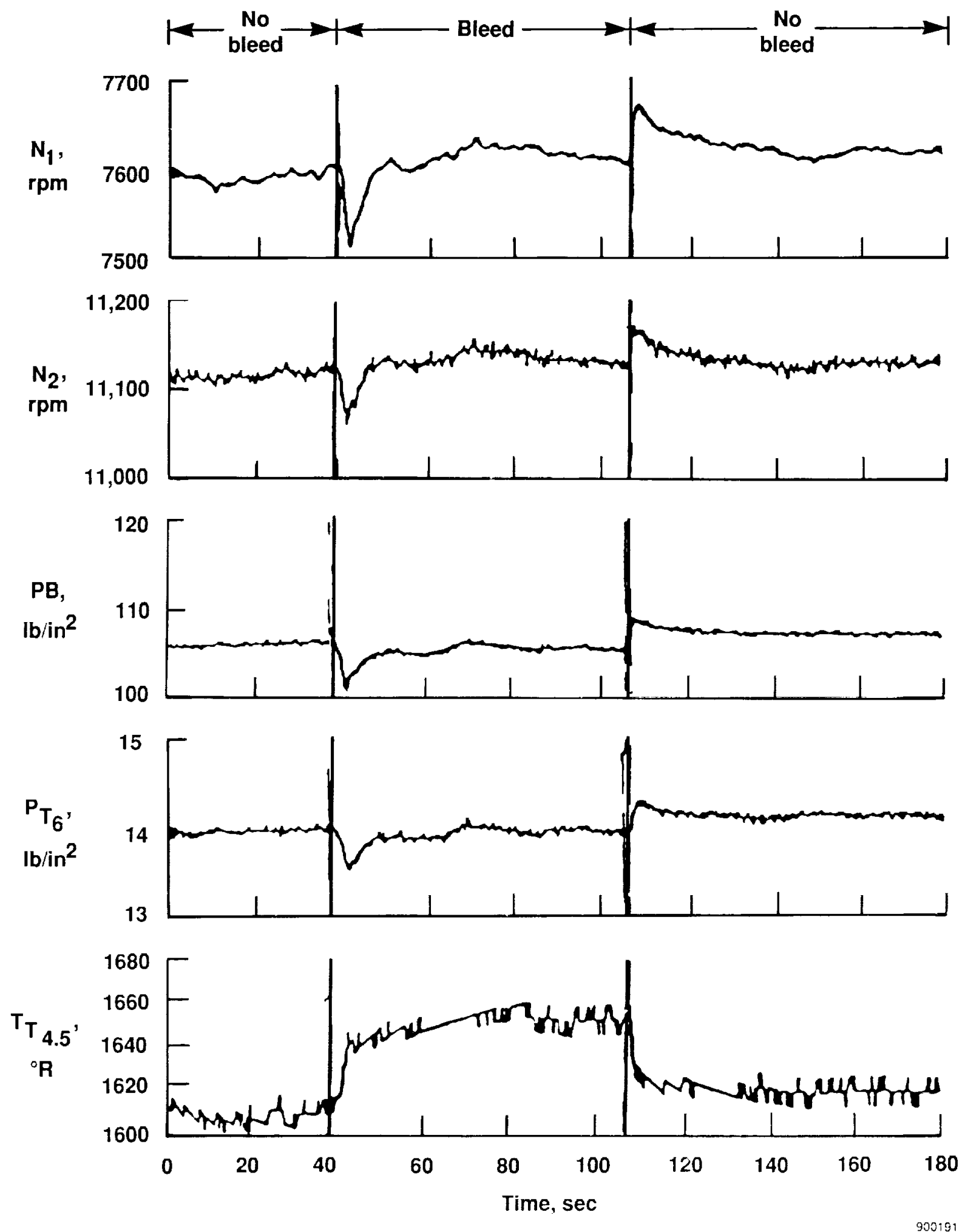

(a) Measured output variables.

Fig. 11 The F-15 airplane measured engine paranclers during compressor bleed variations at Mach 0.90 , an altitude of $30,000 \mathrm{ft}$, and PLA $=43^{\circ}$. 

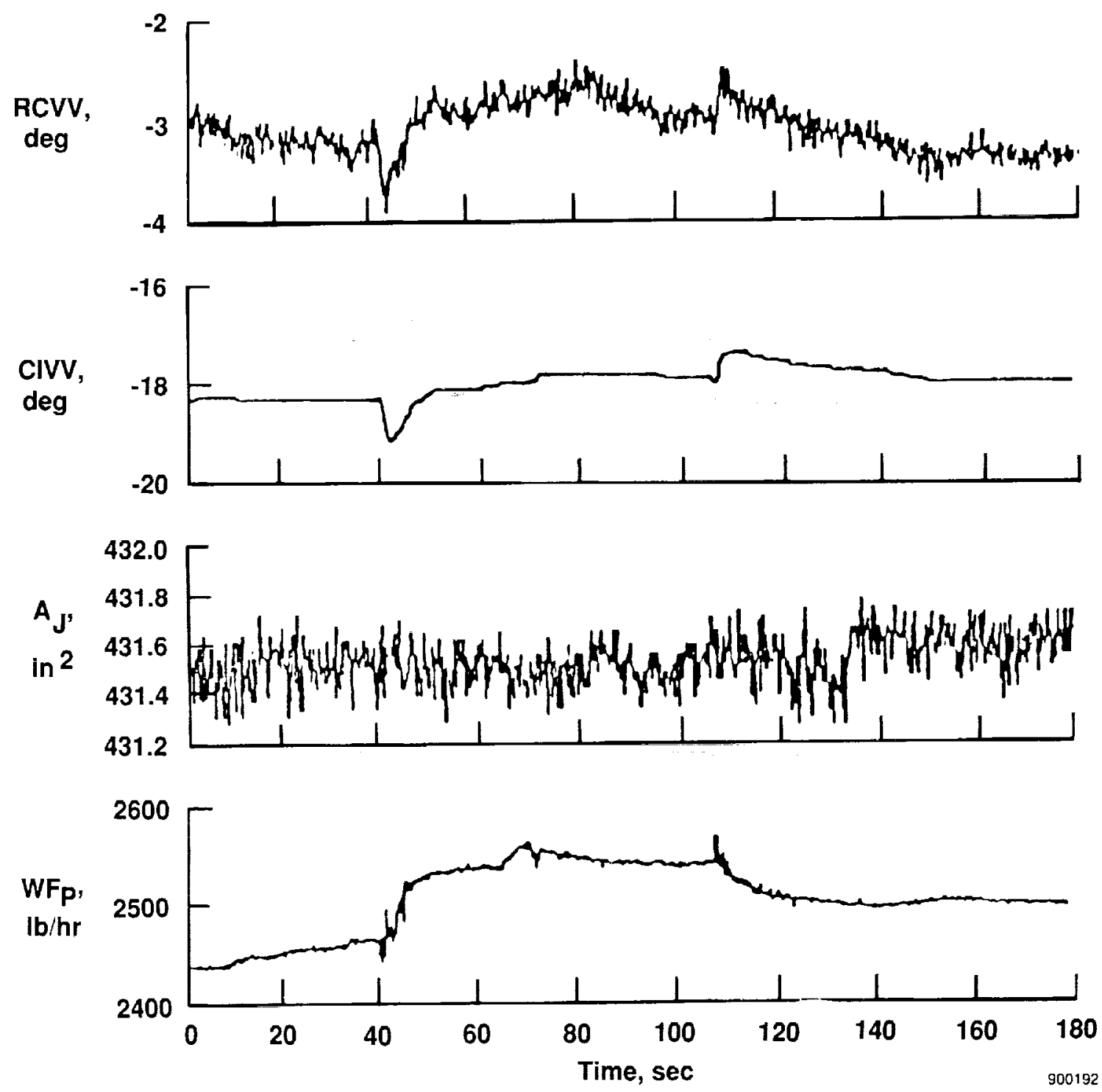

(b) Mcasured control variables.

Fig. 11 Concluded. 
— Measured

--- Estimated
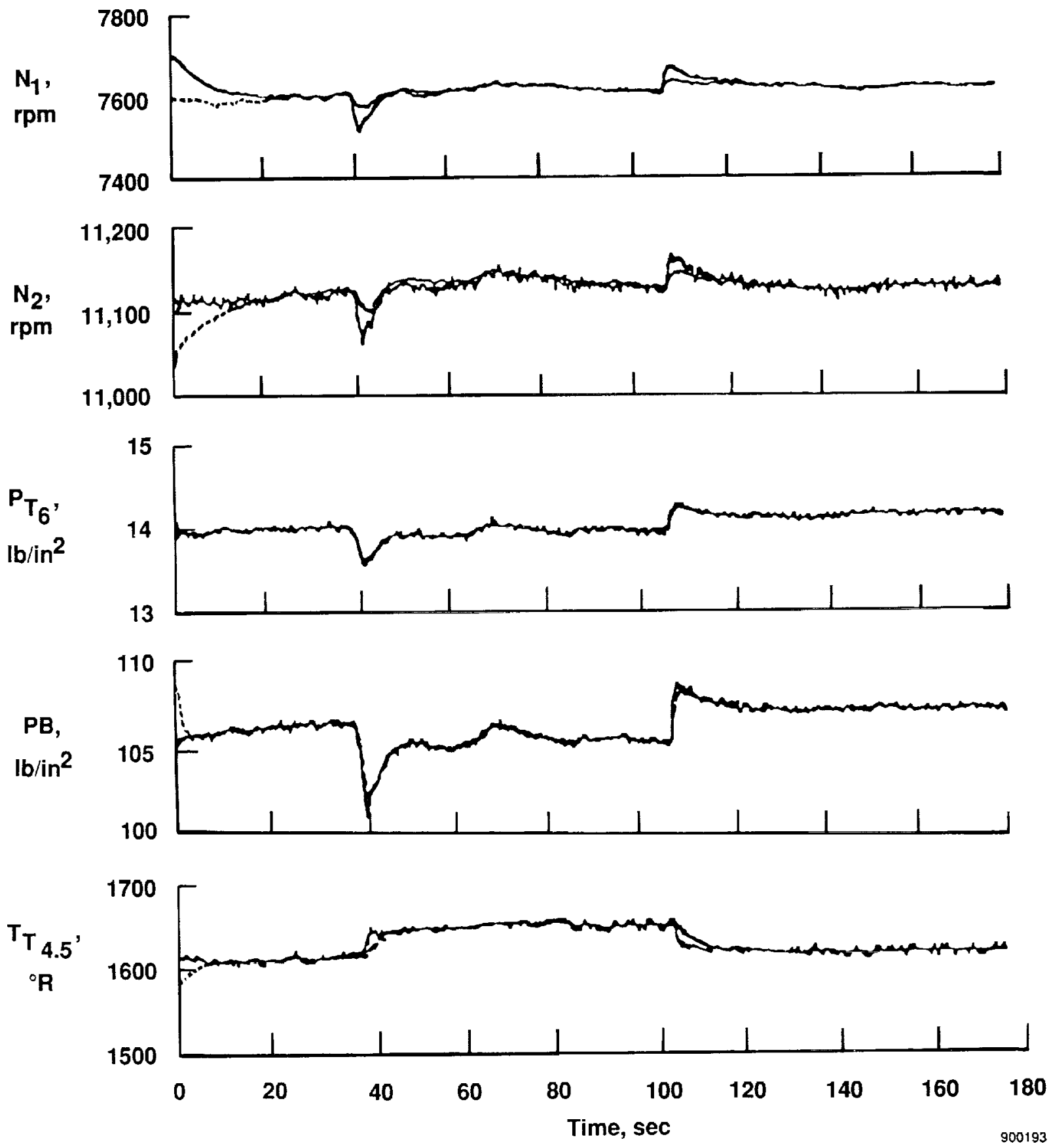

(a) Output estimates.

Fig. 12 The F100 engine parameter estimates from the flight data in Fig. 11. 

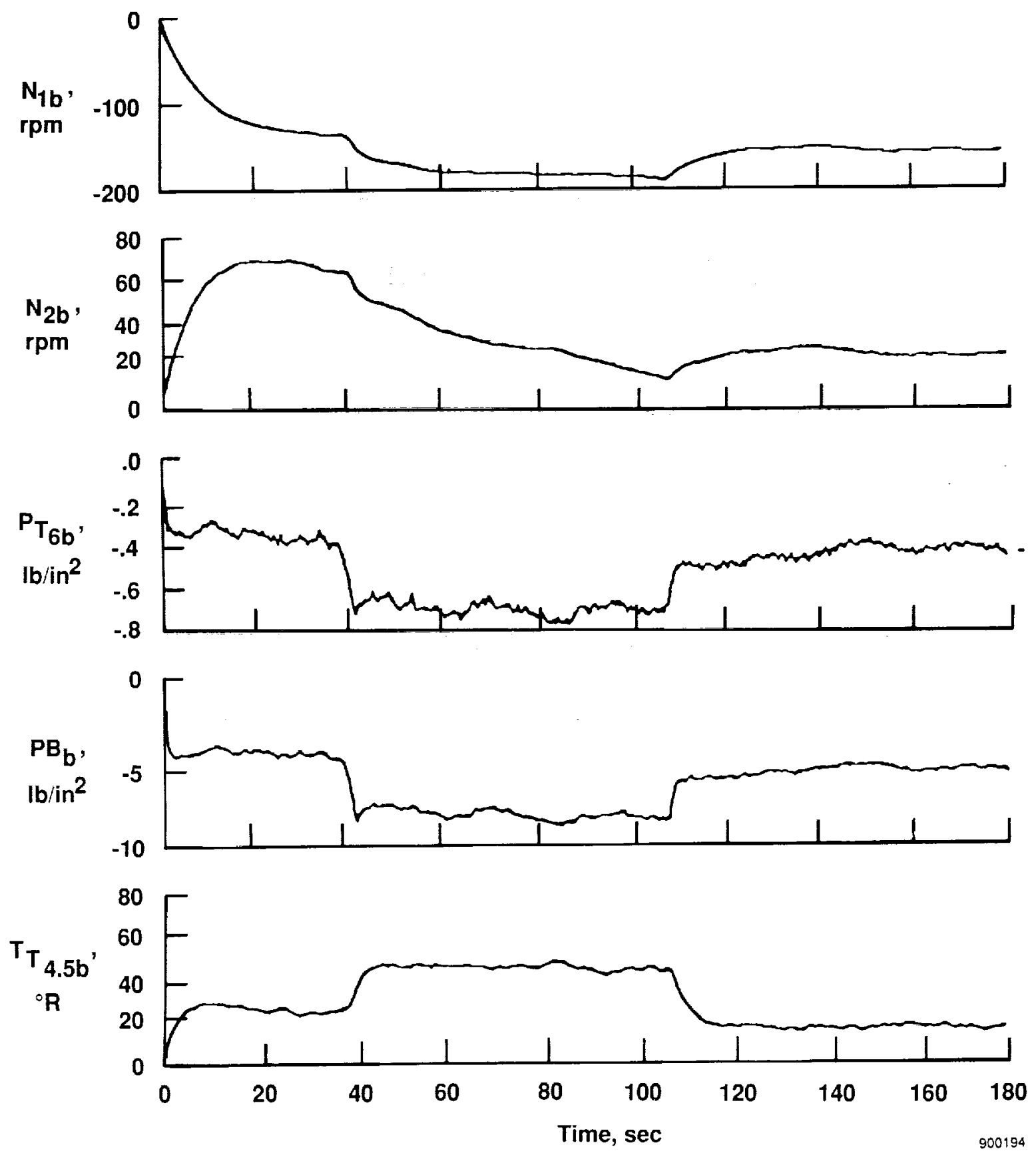

(b) Bias estimates.

Fig. 12 Concluded. 

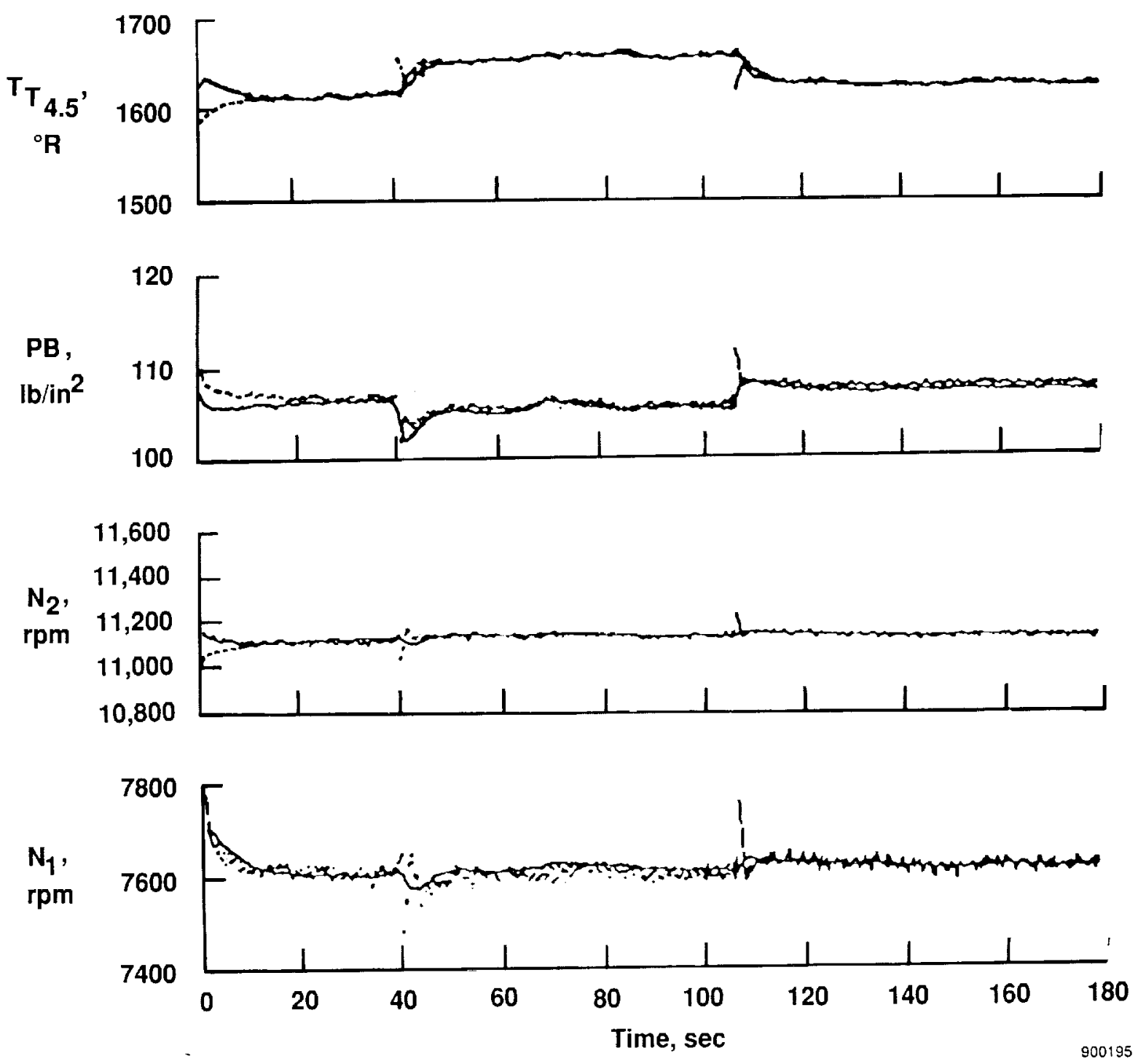

Fig. 13 Proposed formulation estimated outputs from fight data compared with CDF formulation estimates from flight data. 


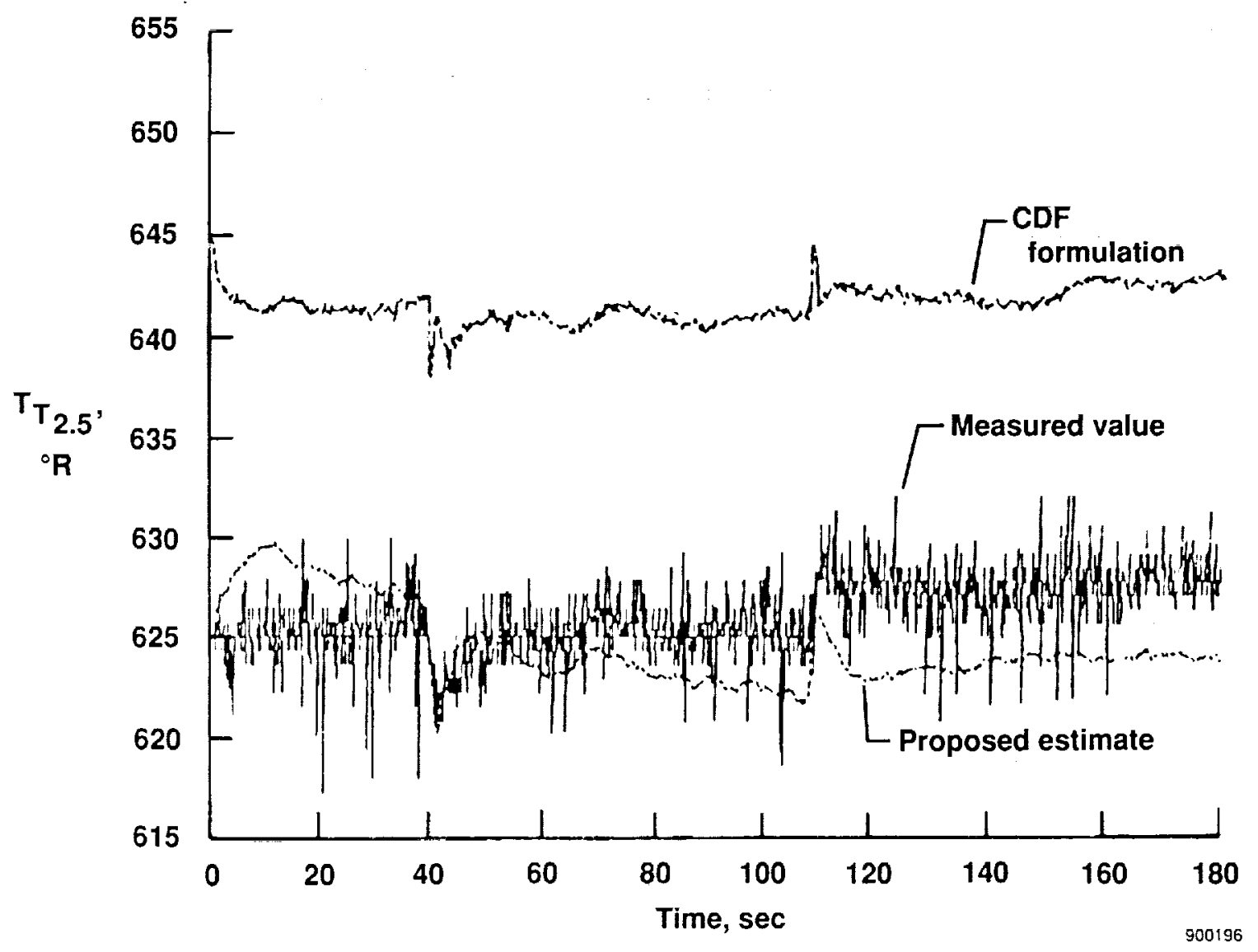

(a) Compressor inlct total temperature cstimates.

Fig. 14 The proposed formulation and the CDF formulation engine parameter estimates from flight data compared with measured engine parameters. 


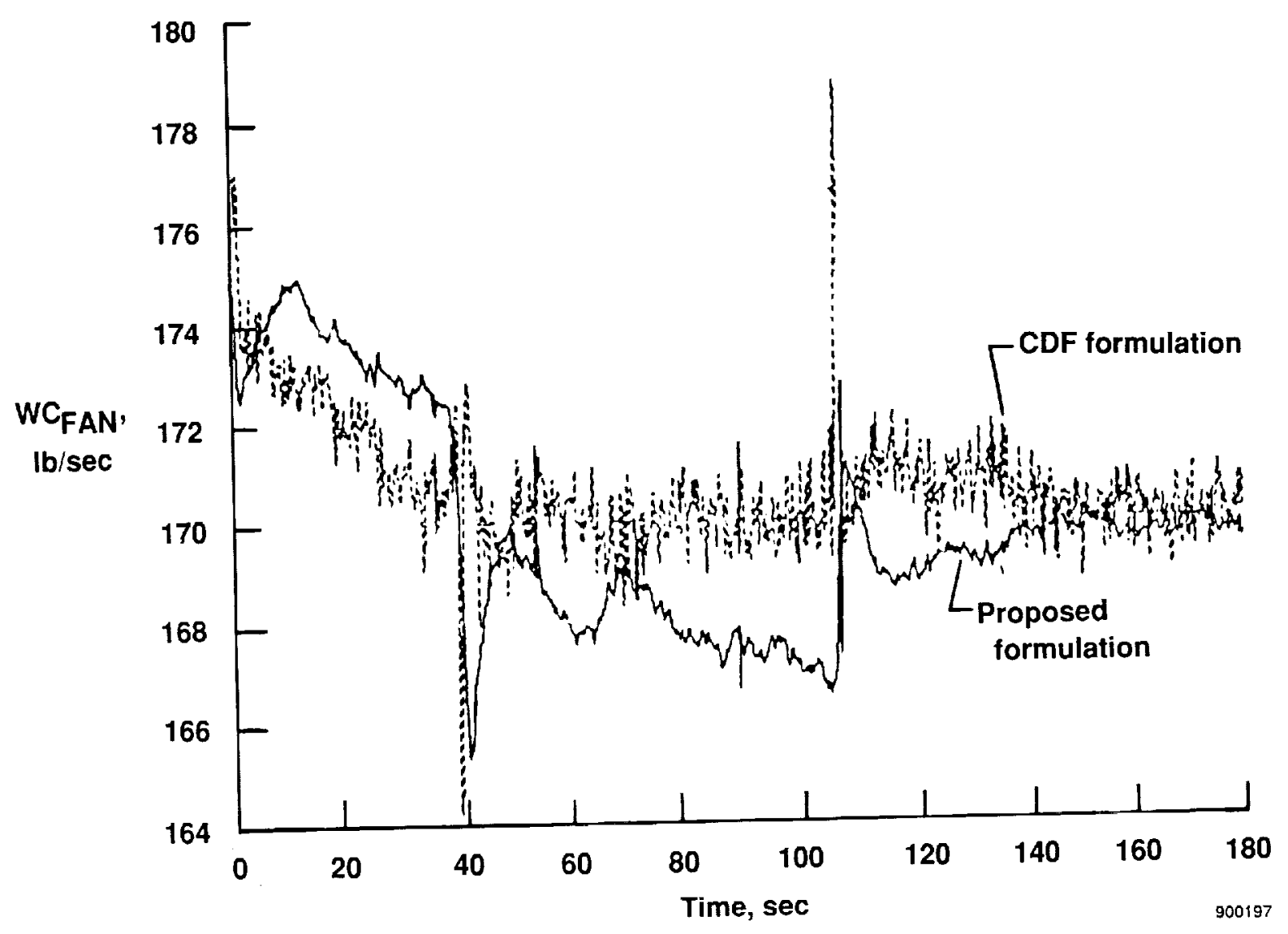

(b) Corrected fan airflow estimates.

Fig. 14 Concluded. 


\begin{tabular}{|c|c|c|c|c|}
\hline NSIN & \multicolumn{4}{|c|}{ Report Documentation } \\
\hline $\begin{array}{l}\text { 1. Report No. } \\
\text { NASA TM-4234 }\end{array}$ & \multicolumn{2}{|c|}{ 2. Government Accession No. } & \multicolumn{2}{|c|}{ 3. Recipient's Catalog No. } \\
\hline \multicolumn{3}{|c|}{$\begin{array}{l}\text { 4. Titte and Subtite } \\
\text { A Proposed Kalman Filter Algorithm for Estimation of } \\
\text { Unmeasured Output Variables for an F100 Turbofan Engine }\end{array}$} & \multicolumn{2}{|c|}{$\begin{array}{l}\text { 5. Report Date } \\
\text { October } 1990 \\
\text { 6. Pertorming Organization Code }\end{array}$} \\
\hline \multicolumn{3}{|c|}{$\begin{array}{l}\text { 7. Author(s) } \\
\text { Gurbux S. Alag and Glenn B. Gilyard }\end{array}$} & \multicolumn{2}{|c|}{$\begin{array}{l}\text { 8. Performing Organization Report No. } \\
\text { H-1639 }\end{array}$} \\
\hline \multicolumn{3}{|c|}{$\begin{array}{l}\text { 9. Performing Organization Name and Address } \\
\text { NASA Ames Research Center } \\
\text { Dryden Flight Research Facility } \\
\text { P.O. Box 273, Edwards, CA } 93523-0273\end{array}$} & \multicolumn{2}{|c|}{ 11. Contract or Grant No. } \\
\hline \multicolumn{3}{|c|}{$\begin{array}{l}\text { 12. Sponsoring Agency Name and Address } \\
\text { National Aeronautics and Space Administration } \\
\text { Washington, DC } 20546-0001\end{array}$} & \multicolumn{2}{|c|}{ 14. Sponsoring Agency Code } \\
\hline \multicolumn{5}{|c|}{$\begin{array}{l}\text { 15. Supplementary Notes } \\
\text { Gurbux S. Alag: PRC System Service, Edwards, California. } \\
\text { Glenn B. Gilyard: Ames Research Center, Dryden Flight Research Facility, Edwards, Cali } \\
\text { Prepared as AIAA } 90-1920 \text { for presentation at AIAA/SAE/ASME/ASEE Joint Propulsion } \\
\text { Conference, Orlando, Florida, July } 16-18,1990 \text {. }\end{array}$} \\
\hline \multicolumn{5}{|c|}{$\begin{array}{l}\text { To develop advanced control systems for optimizing aircraft engine performance, unmeasurable output } \\
\text { variables must be estimated. The estimation has to be done in an uncertain environment and be adaptable } \\
\text { to varying degrees of modeling errors and other variations in engine behavior over its operational life cycle. } \\
\text { This paper presents an approach to estimate unmeasured output variables by explicitly modeling the } \\
\text { effects of off-nominal engine behavior as biases on the measurable output variables. A state variable model } \\
\text { accommodating off-nominal behavior is developed for the engine, and Kalman filter concepts are used to } \\
\text { estimate the required variables. Results are presented from nonlinear engine simulation studies as well as } \\
\text { the application of the estimation algorithm on actual flight data. The formulation presented has a wide range } \\
\text { of application since it is not restricted or tailored to the particular application described in the paper. }\end{array}$} \\
\hline \multicolumn{2}{|c|}{$\begin{array}{l}\text { 17. Key Words (Suggested by Author(s)) } \\
\text { Aircraft engine performance, Off-nominal engine } \\
\text { performance, Kalman filter, Bias estimation, } \\
\text { Unmeasurable output estimation }\end{array}$} & \multicolumn{3}{|c|}{$\begin{array}{l}\text { 18. Distribution Statement } \\
\text { Unclassified-Unlimited }\end{array}$} \\
\hline $\begin{array}{l}\text { 19. Security Classif. (of this report) } \\
\text { Unclassified }\end{array}$ & $\begin{array}{l}\text { 20. Security Classif. (of } \\
\text { Unclassified }\end{array}$ & $\overline{9 \theta)}$ & $\begin{array}{c}\text { 21. No. of Pages } \\
32\end{array}$ & $\begin{array}{r}\text { 22. Price } \\
\mathrm{A} 03\end{array}$ \\
\hline
\end{tabular}

